Analysis of Recent Manifests for Goods Imported through US Ports

M.-A. Descalle, D. Manatt, D. Slaughter

October 31, 2006 
This document was prepared as an account of work sponsored by an agency of the United States Government. Neither the United States Government nor the University of California nor any of their employees, makes any warranty, express or implied, or assumes any legal liability or responsibility for the accuracy, completeness, or usefulness of any information, apparatus, product, or process disclosed, or represents that its use would not infringe privately owned rights. Reference herein to any specific commercial product, process, or service by trade name, trademark, manufacturer, or otherwise, does not necessarily constitute or imply its endorsement, recommendation, or favoring by the United States Government or the University of California. The views and opinions of authors expressed herein do not necessarily state or reflect those of the United States Government or the University of California, and shall not be used for advertising or product endorsement purposes.

This work was performed under the auspices of the U.S. Department of Energy by University of California, Lawrence Livermore National Laboratory under Contract W-7405-Eng-48. 


\title{
Analysis of Recent Manifests for Goods Imported through US Ports
}

\author{
Marie-Anne Descalle, Doug Manatt, Dennis Slaughter,
}

\begin{abstract}
Several active interrogation techniques are being developed to detect shielded special nuclear materials (SNM) hidden in cargo containers loaded on container ships arriving at US ports. It raises the questions of the types of cargos in which SNM could be hidden, and their impact on detected signatures. Since the definition of a set of "typical" or standard cargos has proven to be difficult, we analyzed shipping manifests for US imports shipped through North American ports collected on 14 days distributed over 12 months. From these data, we generated several distribution functions such as commodity categories, average densities, and packaging types that could be of interest to the cargo scanning community.

One of the cargo scanning techniques currently under development at LLNL is based on neutron active interrogation, and relies on the unique signature of beta-delayed gammas emitted by fission products in the 3 to $7 \mathrm{MeV}$ energy range. ${ }^{19} \mathrm{~F}(\mathrm{n}, \mathrm{a}){ }^{16} \mathrm{~N}$, has been identified as the main potential interference for 7 and $9 \mathrm{MeV}$ neutron beams. Estimates of cargo compositions based on manifests identified as containing fluorine are presented.
\end{abstract}

\section{INTRODUCTION}

The detection of smuggled nuclear material in sea-going shipping containers using imaging and active interrogation techniques has been identified as a necessity but it is also a complex problem, mainly due to the variety of cargos shipped in containers. Defining a "standard cargo" or a standard cargo composition has proven elusive at best. However, due to the rapid growth of containerized commerce over the past few years, it is crucial to understand the types of cargos or commodities being shipped to the US. Currently, container ships represent $7 \%$ of the world commercial fleet [1]. In 2005, 17 million TEU were imported to the US via 44 ports, according to the maritime administration.[2] We analyzed a dataset of container ship manifests and extracted various distributions of interest to cargo scanning projects from research and development techniques to system studies. In the first section, we define various terms that will be used in the text. The data set of containerized US imports is presented in section 2 , and the analysis of US imports is given in section 3.

Several active interrogation techniques have been proposed to detect the presence of SNM in cargo containers, one of the techniques developed at Lawrence Livermore National Laboratory probes a container with a $7 \mathrm{MeV}$ neutrons beam, and is based on the detection of the specific signature of beta delayed gamma rays emitted by fission products in the 3 to $7 \mathrm{MeV}$ range.[3][4][5][6] Within that energy range, ${ }^{16} \mathrm{~N}$, created through the reaction ${ }^{19} \mathrm{~F}(\mathrm{n}, \mathrm{a}){ }^{16} \mathrm{~N}$, has been identified as the main potential interference since it emits a gamma line at $6.1 \mathrm{MeV}$.[7] In the last section of the study, we focus on records of commodities identified as containing fluorine.

\section{DEFINITIONS}

Here, we define terms that are commonly used in the container shipping industry and in this report.

TEU stands for Twenty Equivalent Unit, and is a unit volume commonly used in the container shipping industry. A TEU represents the known volume of a $6 \mathrm{~m}$ (20 feet) container of standard internal dimension $2.35 \mathrm{~m}$ wide x 2.4 $\mathrm{m}$ high x $5.9 \mathrm{~m}$ long, with a volume close to $33.13 \mathrm{~m}^{3}$, and a payload of 21.6 metric tons. The total load is 24 metric tons and includes both cargo and container weights. 
HS code stands for Harmonized System codes. It is a commodity classification code used to establish international commodity tariffs. There are 21 broad categories, 97 sub-categories numbered from 1 to 97 and described by a two digit code. Note that there is no commodity assigned to HS code 77. Each of these categories are further refined into more than 2000 categories, described by a four digit code, an additional level of detail can be attained by using a seven digit code corresponding to over 4000 commodities. Examples of the 2 and 4 digit codes are shown in figure 1, and a complete list of commodities is given in appendix A.[8] For this study, we used the 4 digit to classify commodities into broad categories.

MANIFEST when a boat arrives at a US port, it is defined as a port call, and the ship is assigned a unique manifest number.

RECORD each record corresponds to a commodity, it does not correspond to a container or a TEU. One record can describe a commodity that occupies a fraction of a container or a commodity shipped in several containers.

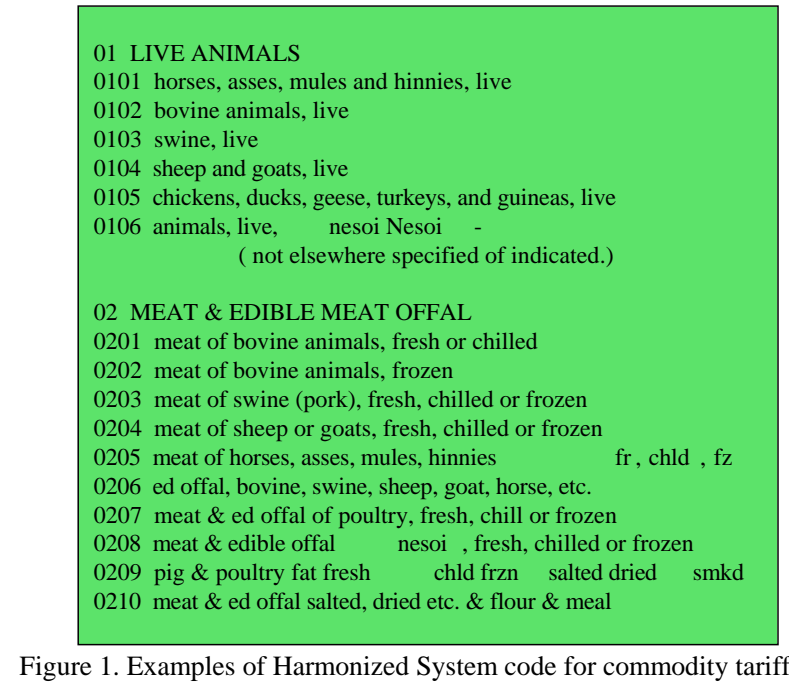

\section{DATA SET}

The data set was obtained from PIERS Global Intelligence Solutions, a private company that "maintains a comprehensive database of import export information on cargos moving through US, Mexico, Latin America and Asia. It collects 25000 bills of lading per day". Import information are collected from two sources, vessel manifest from shipping companies and US customs automated manifest systems data tapes from all US ports. PIERS integrates, checks, and reconciles discrepancies between the two databases.[9]

The goal of this study is to analyze a PIERS US import data set to understand containerized cargo traffic and some of cargo material composition. The data set consists of the entire records of all international container imports into the USA that were acquired for 14 separate days over a 12-month period from July 2004 to June 2005 by selecting the highest volume days each month and also including the two next highest volume days from the 12 Month. The dataset contains almost half a million individual records of specific commodities imported through US ports. Each record contains 38 fields such as date, ports of departure and entry, commodity descriptions and categories, HS codes and description, type of containers, number of containers, cargo volume and volume in TEU, number and type of packaging, and the total weight of cargo. The 38 fields represent a subset of the available data collected by PIERS for each commodity. The full list of fields is given in Appendix B.

The quality of the data set is limited by human error, whether voluntary or not, during the various stages of data entry. We observed typing errors in the commodity description fields, wrongly assigned commodity codes, empty fields (such as cargo volume). Finally we discarded all records with the commodity description "cargo container" when calculating densities. The common practice in the shipping industry is to add one such record per manifest. However, these records have no information, since most fields are empty.

We analyzed the data in two ways. We used the HS code to determine global trends of US imports, e.g. the main 
ports of entry or commodities. To analyze the containerized traffic of specific commodities, we used keyword and variations of that keyword to analyze the commodity description and HS commodity description. We initially thought we could rely solely on the commodity description, however this approach proved daunting due to the many variations observed for a given commodity. As shown in table 1 and 2, the data set consists of nearly half a million records, that can be grouped into 1121 categories based on the four-digit HS code, but there are close to $1.5 \mathrm{e}+5$ unique commodity descriptions.

TABLE 1: SCAN THROUGH THE COMMODITY DESCRIPTIONS

\begin{tabular}{|r|l|}
\hline 146432 & Unique commodity descriptions \\
\hline 744 & PIERS 4-digit commodity identifiers and standardized description \\
\hline 1433 & PIERS 7-digit commodity identifiers and standardized description \\
\hline 1121 & 4-digit Harmonized Tariff code and descriptions \\
\hline 3611 & 7-digit Harmonized Tariff codes \\
\hline 3598 & Standardized Harmonized Tariff code description \\
\hline
\end{tabular}

Results of the data analysis are given in total number of TEU over 14 days or in \% of total TEU, based on the assumption that cargo volume is the most relevant quantity for scanning techniques. An overview of the data set is given in table 2. A summary of the total number of records, cargo weight and TEU is given in table 3 for each of the 14 days. The increased traffic seen on 10/12/14 is due to a significant increase of US import at the port of Long Beach. One should be careful when extrapolating these numbers to imports per year. It would almost certainly lead to an overestimation of actual imports since we used the highest volume days of each month, unless shipping volume has increased dramatically since 2004/2005.

TABLE 2: DATA SET AT A GLANCE

\begin{tabular}{|r|l|}
\hline 14 & Days of cargo import data \\
\hline 496990 & Total number of records \\
\hline 480512 & Unique records \\
\hline 471004 & $\begin{array}{l}\text { Records from which the mean cargo } \\
\text { density can be evaluated }\end{array}$ \\
\hline 44 & USA import ports \\
\hline 149 & USA final destination \\
\hline 325 & Fountries of origin ports of origin \\
\hline
\end{tabular}

TABLE 3: SUMMARY PER US ENTRY DATE

\begin{tabular}{|c|c|c|c|}
\hline $\begin{array}{c}\text { Days of } \\
\text { Entry }\end{array}$ & $\begin{array}{c}\text { Records } \\
\text { [\#] }\end{array}$ & $\begin{array}{c}\text { Volume } \\
\text { [TEU] }\end{array}$ & $\begin{array}{c}\text { Weight } \\
\text { [metric tons] }\end{array}$ \\
\hline $07 / 23 / 04$ & 35936 & 67795 & 439548 \\
\hline $08 / 20 / 04$ & 36730 & 68771 & 439387 \\
\hline $09 / 27 / 04$ & 33105 & 66216 & 421285 \\
\hline $10 / 12 / 04$ & 44136 & 84775 & 562455 \\
\hline $11 / 26 / 04$ & 33563 & 61917 & 436187 \\
\hline $12 / 10 / 04$ & 27840 & 51198 & 357810 \\
\hline $01 / 28 / 05$ & 32193 & 58969 & 429731 \\
\hline $02 / 18 / 05$ & 36392 & 60201 & 412580 \\
\hline $03 / 18 / 05$ & 31717 & 62062 & 411568 \\
\hline $04 / 01 / 05$ & 34620 & 62932 & 439350 \\
\hline $05 / 20 / 05$ & 35726 & 65448 & 453639 \\
\hline $05 / 27 / 05$ & 35621 & 66483 & 450471 \\
\hline $06 / 03 / 05$ & 39333 & 74637 & 515750 \\
\hline $06 / 10 / 05$ & 40384 & 75047 & 500975 \\
\hline Total & 497,295 & 926,450 & $6,270,736$ \\
\hline
\end{tabular}




\section{REsUlts}

\section{A. Ports of Arrival}

All US container imports arrive at 44 US ports given in figure 1. Figure 2 shows that 12 US ports handle more than $94 \%$ of traffic in TEU, of which, 65\% are on the West coast and $29 \%$ on the East coast. The ports of Los Angeles and Long Beach alone handle a staggering 47\%, almost half of the total US imports, due to the prevalence of Asian imports. This seems to indicate that, as a first step, we can focus secondary screening on just a few US ports rather than on all 44.

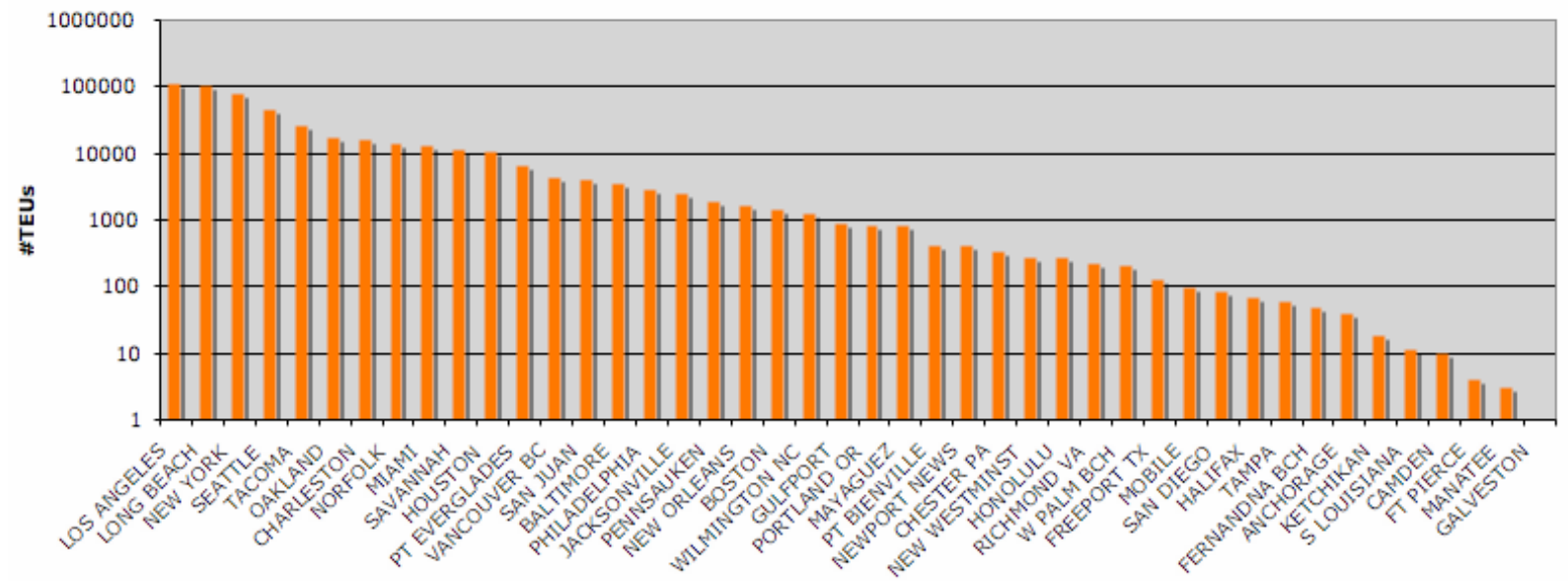

Figure 2. Total number of TEUs imported through 44 US ports.

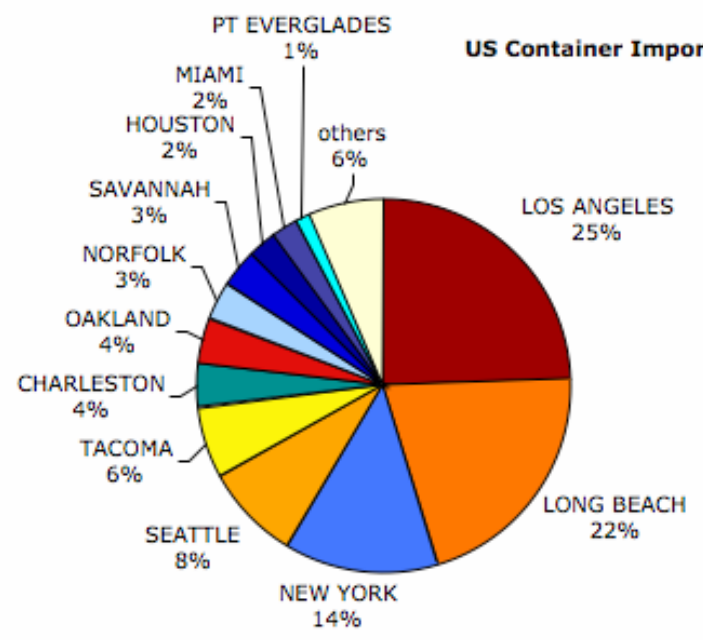

Figure 3. US container imports per ports in \% of total TEU 


\section{B. Imported Commodities}

Table 4 and figure 4 summarize the 21 main commodity categories and their relative importance. The " 00 " category is used by shippers and include "Household goods", "Miscellaneous cargo", and "cargo containers" , however it is not part of the Harmonized System. Toys and furniture, textiles, plastic and rubber are respectively first, third and fifth in volumes while machinery \& mechanical appliances, and base metal \& article of base metals are second and fourth respectively. 28\% of commodities are metal based. Assuming that most furniture and toys are made of wood and plastics, organic products, where "organic" is broadly defined as mainly composed of CHON, represent close to $60 \%$ of US imports. The remaining $12 \%$ consists of products made of stone, ceramics, mineral products, work of art and so on. There are four categories accounting for nearly half of the total traffic by volume: furniture \& toys, heavy machinery, textiles, and base metals. Further details based on the two digits HS code are given in figure 5 for three of these categories.
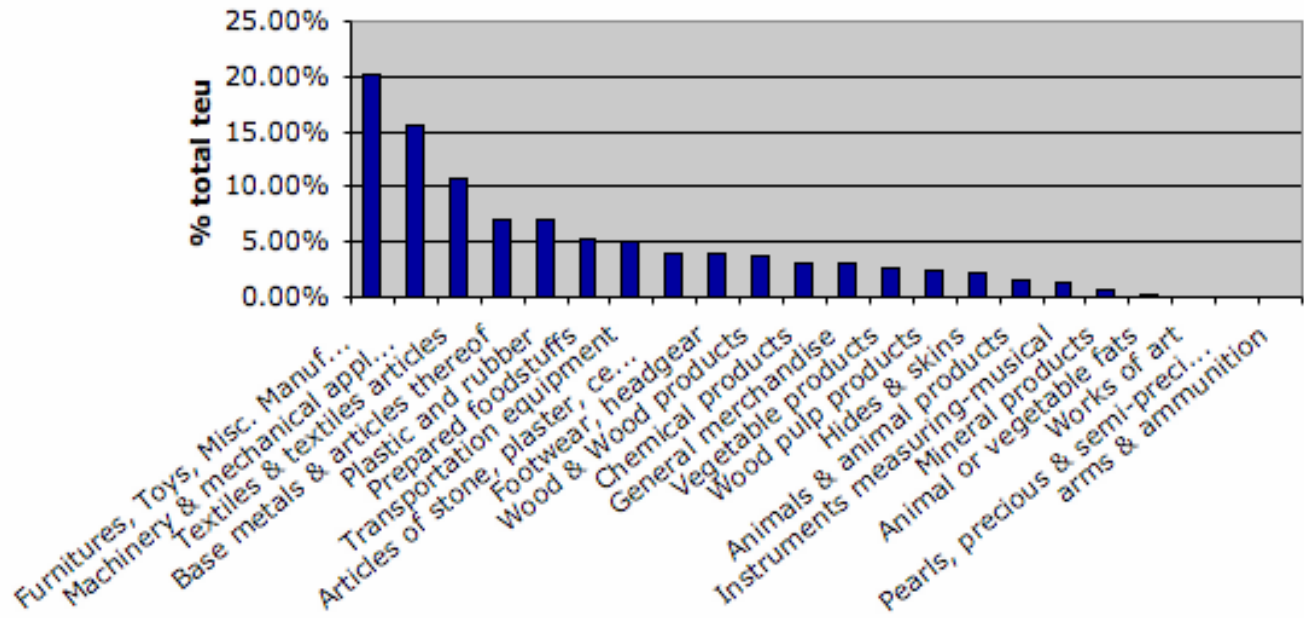

Figure 4. Main US imports

TABLE 4: US IMPORTS RANKING

\begin{tabular}{|l|l|c|}
\hline HS code & \multicolumn{1}{|c|}{ categories } & [\% TEU] \\
\hline $00-00$ & General merchandise & $3.09 \%$ \\
$01-05$ & Animals \& animal products & $1.60 \%$ \\
$06-14$ & Vegetable products & $2.66 \%$ \\
15 & Animal or vegetable fats & $0.15 \%$ \\
$16-24$ & Prepared foodstuffs & $5.29 \%$ \\
$25-27$ & Mineral products & $0.63 \%$ \\
$28-38$ & Chemical products & $3.12 \%$ \\
$39-40$ & Plastic and rubber & $7.00 \%$ \\
$41-43$ & Hides \& skins & $2.24 \%$ \\
$44-46$ & Wood \& Wood products & $3.64 \%$ \\
$47-49$ & Wood pulp products & $2.47 \%$ \\
$50-63$ & Textiles \& textiles articles & $10.75 \%$ \\
$64-67$ & Footwear, headgear & $3.98 \%$ \\
$68-70$ & Articles of stone, plaster, cement, asbestos & $4.00 \%$ \\
& Pearls, precious \& semi-precious stones, & \\
71 & metals & $0.05 \%$ \\
$72-83$ & Base metals \& articles thereof & $7.11 \%$ \\
$84-85$ & Machinery \& mechanical appliances & $15.48 \%$ \\
$86-89$ & Transportation equipment & $5.04 \%$ \\
$90-92$ & Instruments measuring-musical & $1.41 \%$ \\
93 & Arms \& ammunition & $0.03 \%$ \\
$94-96$ & Furnitures, Toys, Misc. Manufac. Articles & $20.18 \%$ \\
97 & Works of art & $0.07 \%$ \\
\hline & &
\end{tabular}



HS 94-97 Furnitures, Toys, Misc.:
$20.18 \%$ total TEU

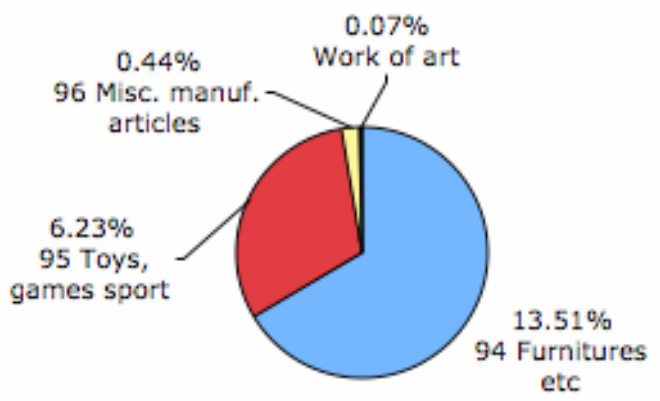

\section{HS 84-85 Heavy Machinery: $15.48 \%$ total TEU}

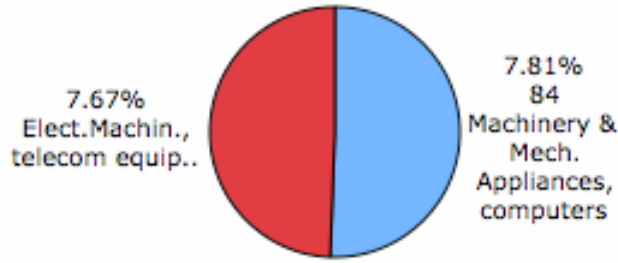

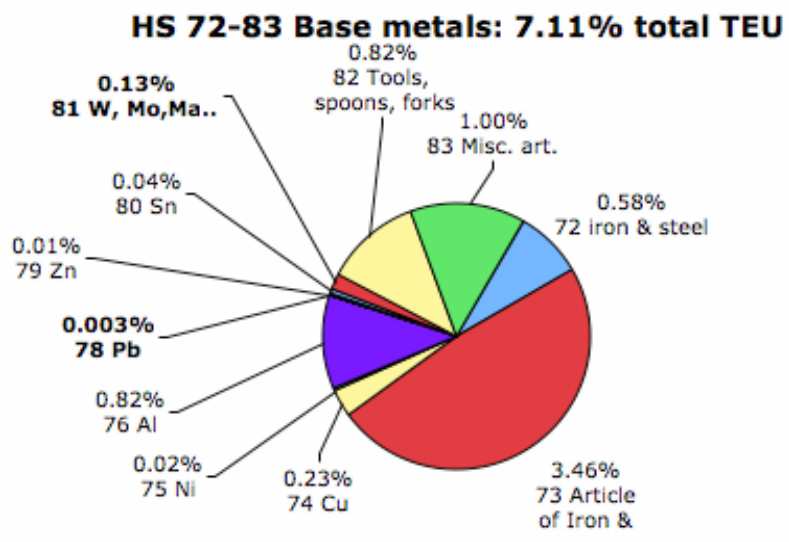

Figure 5. Three categories of US imports (details in \%TEU)

\section{Cargo Density}

1) Average density

The density averaged over a TEU is calculated for each record with non-zero weight and TEU, based on equation 1:

$$
\rho=\text { weight } /\left(V_{T E U} * N\right)
$$

where $\mathrm{V}_{\text {TEU }}$ is the volume of a 20 foot container and $\mathrm{N}$ is the number of TEU. A plot of \% of total TEU versus cargo average density is shown in figure 6, for all 14 days combined. Interestingly, the density distribution has the same characteristics on any given day. The mean cargo density is just under $0.2 \mathrm{~g} / \mathrm{cm}^{3}$. This is consistent with the value obtained by dividing the total mass of commodities by the total number of TEU imported to the US (table 3), which predicts that on average, the cargo weight is 6.7 metric tons per TEU, for a density close to $0.2 \mathrm{~g} / \mathrm{cm}^{3}$. The 20 feet volume is $33.13 \mathrm{~cm}^{3}$ and its maximum loading capacity is 21.6 metric tons, for a maximum average cargo density of $0.65 \mathrm{~g} / \mathrm{cm}^{3}$. $~ 98 \%$ of densities shown here are below the theoretical limit of $0.65 \mathrm{~g} / \mathrm{cm}^{3}$. The mean density is driven by the relative importance of commodities with densities around $0.1 \mathrm{~g} / \mathrm{cm}^{3}$. Low density cargos should be more easily cleared by radiographic primary screening systems. Secondary screening techniques will end up being necessary for higher density commodities due to their opacity to the radiographic probe beams. A very large portion of the container cargo is under $0.4 \mathrm{~g} / \mathrm{cm}^{3}$ in average density, these containers are likely to be cleared by primary radiographic screening. This will leave a small fraction of the containers to be processed by secondary screening techniques. 


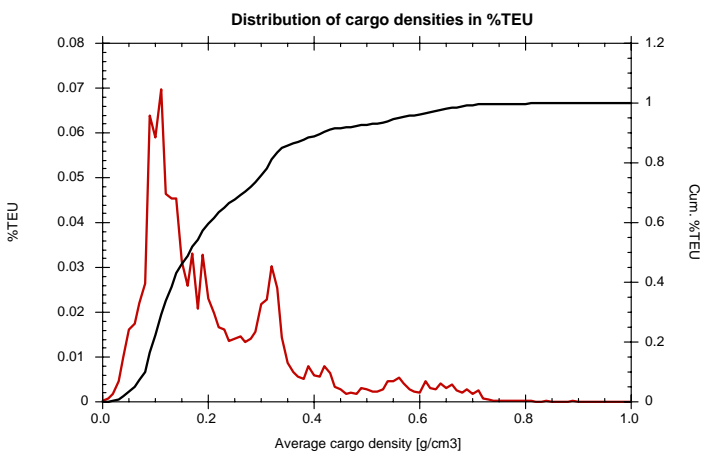

Figure 6. Distribution of average cargo density

\section{2) Density and HS code}

We have identified the most important materials in each range of interest. Figure 7 shows the distribution of number of records on the vertical axis as a function of average cargo density in $\mathrm{g} / \mathrm{cm}^{3}$ and 4-digit HS code, for densities in the ranges [0-0.2], [0.2-0.4], [0.4-0.6], and $>0.6 \mathrm{~g} / \mathrm{cm}^{3}$. The peak observed at $0.1 \mathrm{~g} / \mathrm{cm}^{3}$ in figure 4 corresponds to the following commodities: furniture and toys (HS 94-95), textiles, footwear and clothing (HS 42, 62-64). This is consistent with the fact that furniture, toys and textiles are among the top three US imports (see table 4). Other commodities of interest with density $<0.2 \mathrm{~g} / \mathrm{cm}^{3}$ are miscellaneous cargo (HS 00), vehicle parts (HS 87) and plastic (HS 39). Between 0.2 and $0.4 \mathrm{~g} / \mathrm{cm}^{3}$, we find paper products (HS 48-49), textiles (HS 52), vehicles and iron articles (HS 73, 84, 87.) and beverages and edible products (HS<22). In the range from 0.4 to $0.6 \mathrm{~g} / \mathrm{cm}^{3}$, two classes of commodities are clearly identifiable. The first group consists of ceramics and stone products (HS 68-69), and articles of iron or steel (HS 73, 84), while the second group consists of salts (HS 25) and edible products such as frozen meat (HS 02), fruit and nuts (HS 20), beverages (HS 22), or coffee (HS 09). In the range from 0.6 to 2 $\mathrm{g} / \mathrm{cm}^{3}$, there are very few commodities with average densities greater than $1 \mathrm{~g} / \mathrm{cm}^{3}$, they correspond to cargos occupying a fraction of a TEU. The main commodities are ceramics and stone products (HS 68-69), articles of iron or steel (HS 73, 83), organic chemicals (HS 29), edible products (HS <22)

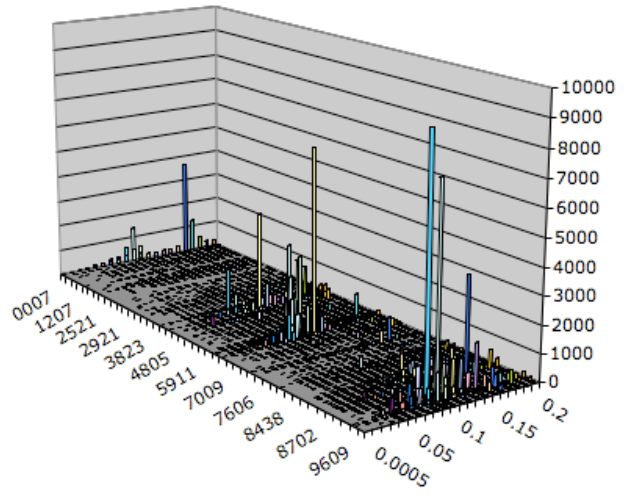

a) $\left[0-0.2 \mathrm{~g} / \mathrm{cm}^{3}\right]$

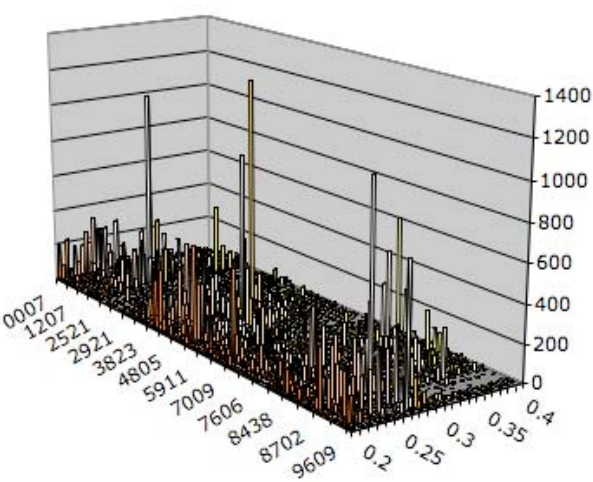

b) $\left[0.2-0.4 \mathrm{~g} / \mathrm{cm}^{3}\right]$ 


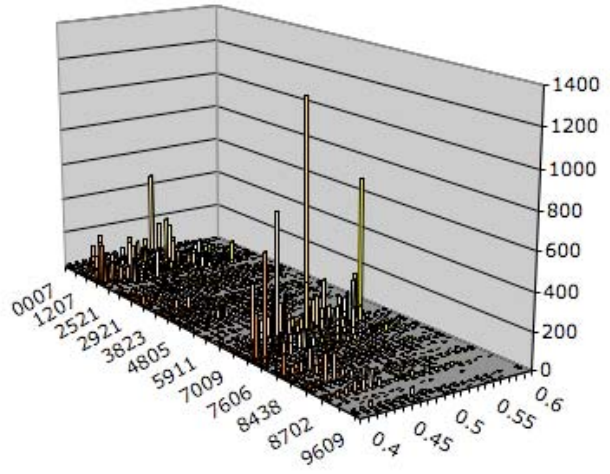

c) $\left[0.4-0.6 \mathrm{~g} / \mathrm{cm}^{3}\right]$

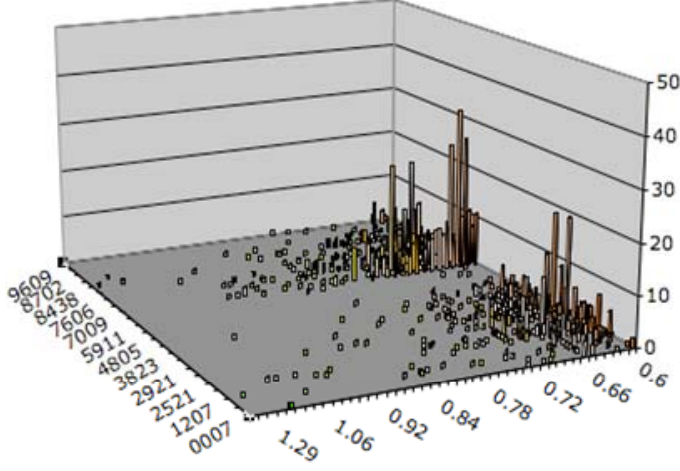

d) $>0.6 \mathrm{~g} / \mathrm{cm}^{3}$

Figure 7. Distributions of number of records for cargo categories given in terms of 4-digit HS code. The distributions are given for four ranges of average cargo density a) $<0.2 \mathrm{~g} / \mathrm{cm}^{3}$ b) 0.2 to $0.4 \mathrm{~g} / \mathrm{cm}^{3}$ c) 0.4 to $0.6 \mathrm{~g} / \mathrm{cm}^{3}$ and d) 0.6 to $2 \mathrm{~g} / \mathrm{cm}^{3}$.

We have generated similar 3D density distributions, normalized or in \% of total TEU, for 2 and 4 digit HS codes, as well as for the broad HS categories given in table 4. These can be used to generate models of container stacks. For example, we can assign a homogenous cargo to each container by sampling a commodity from the commodity distribution and a density from its corresponding density distribution. Existing processed data is available and can be obtained by contacting the authors.

\section{Containers}

As mentioned earlier, 38 fields are associated with each record or commodity, three of which are the container type expressed in term of length in foot, the number of containers and the number of TEUs being shipped. A container size, or length can vary from 20 to 53 feet. When there is no information available on the container size, shippers can enter two additional categories - ZZ for unknown size and LC for partially filled. We observed that the "partially filled" or LC label can be misleading, since it can correspond to a large number of TEUS. Note that, for commodities occupying a fraction of a container, the records in our data set do not have the information needed for us to determine which commodities were loaded together in a given container.

In figure 8a, we can observe two distributions when the container size is given in TEU. In figure 8b, are plotted the distribution of 20,40,45, 48, and 53 feet containers. We did not include records for which the container size was unspecified or for partially filled containers. The plot shows that $\sim 70 \%$ of records give containers as 40 foot long, while $24 \%$ are 20 footers, $5 \%$ are 45 footers. Interestingly, the payload of a 20 and 40 foot containers are not very different, they are 21 and 27 metric tons respectively. 40 footers are likely to be used to ship large quantity of low density products, e.g. tee-shirts, while 20 footers can be used for denser commodities, e.g. marble slabs .
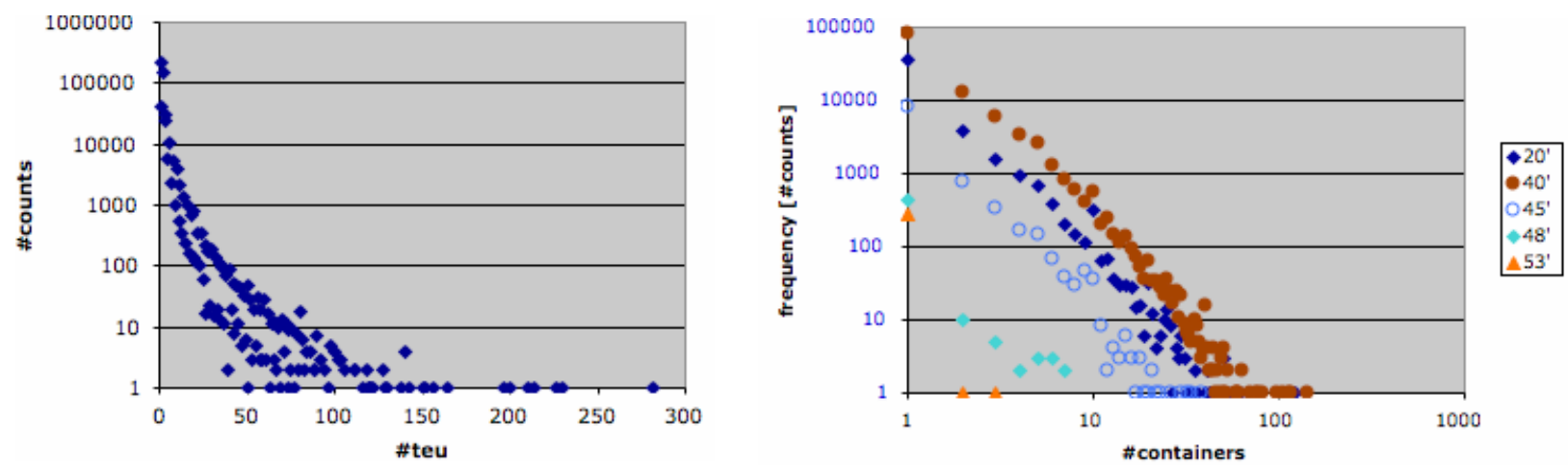

Figure 8. Distribution of shipping containers per record a) in TEU and b) sorted by container size 
Table 5 shows the breakdown of US import in \% of total TEU by container size. It is likely that a large proportion of containers falling in the "LC" or "ZZ" category are 40 footers.

TABLE 5: US IMPORTS SORTED BY CONTAINER SIZE

\begin{tabular}{|c|c|c|c|c|c|c|c|c|c|}
\hline Container Size & 40 & LC & ZZ & 20 & 45 & 48 & 53 & 22 & 43 \\
\hline \%TEU & $45.13 \%$ & $33.28 \%$ & $10.00 \%$ & $7.76 \%$ & $3.60 \%$ & $0.15 \%$ & $0.08 \%$ & $0.001 \%$ & $0.001 \%$ \\
\hline
\end{tabular}

\section{E. Known Sources of Interferences}

Several classes of commodities have been identified as potential sources of false alarms in radiation portal monitors installed at US borders. They are divided into Naturally Occurring Radiation (NORM) sources, medical and industrial sources and shipments related to the nuclear fuel cycle. NORM sources contain ${ }^{40} \mathrm{~K},{ }^{235} \mathrm{U},{ }^{232} \mathrm{Th}$ and ${ }^{226} \mathrm{Ra}$. In particular, these can be found in rocks, salts and ceramics, bananas and fertilizer. Total volume in TEU, total mass, packaging information when available and the number of day with such records are summarized in table 6. The last column is an extrapolation in terms of number of days per year. In the PIERS data set, ceramics are by far the largest NORM import, with 2.31\% of all TEU, and over half of ceramic tiles and tableware are declared as "glazed ceramics". In the past, some of the glazed ceramics known as "fiesta ware" contained significant amount of ${ }^{235} \mathrm{U}$ used as a pigment.

US Banana imports are significant, they represent $0.42 \%$ of all imports and arrive daily. Banana shipments usually fill 40 foot containers, the cargo mass is around 15 metric tons of bananas/TEU, containing about $54 \mathrm{~kg}$ of potassium.[10] A class of fertilizers called potash is another common source of potassium, they have their own category in the HS code. Potash contains 30 to $60 \%$ of $\mathrm{K}_{2} \mathrm{O}$. We also included data for a class of fertilizer for which the active ingredient is "unspecified" which means that it is a combination of nitrogen, phosphate and potassium, or N-P-K.

The PIERS data set contained a few occurrences of radioactive sources and products linked to the fuel cycle. They were all coming from Europe, in the form of uranium metal from Spain, cylinders of UF 6 for fuel enrichment from the EU, and uranium from Russia. Radioactive materials were identified as sources but there was no details regarding isotopes or source strength. These occurrences are rare and one hopes that they are strongly regulated, protected and under strict surveillance at all time.

TABLE 6: INTERFERENCES

\begin{tabular}{|c|c|c|c|c|c|c|c|c|}
\hline Product & Origin & Packaging & TEU & $\begin{array}{c}\text { Weight } \\
\text { [ton] }\end{array}$ & $\begin{array}{c}\text { \#day } \\
\text { s }\end{array}$ & $\begin{array}{c}\text { TEU } \\
{[\%} \\
\text { total] }\end{array}$ & $\begin{array}{c}\text { Weight } \\
\text { [\%total] }\end{array}$ & $\begin{array}{c}\text { \#days/ } \\
\mathrm{y}\end{array}$ \\
\hline Rock/Salt & & & 4511 & 73989 & 14 & 0.49 & 1.18 & 364 \\
\hline Cut stones & & & 5331 & 84730 & 14 & 0.58 & 1.35 & 364 \\
\hline Ceramics & & & 21372 & 264056 & 14 & 2.31 & 4.31 & 364 \\
\hline Bananas & $\begin{array}{l}\text { South, central } \\
\text { Am. }\end{array}$ & $\begin{array}{l}\text { Boxes, cartons, } \\
\text { cases }\end{array}$ & 3919 & 32348 & 14 & 0.42 & 0.52 & 365 \\
\hline Fertilizer (K) & EU, Israel & Bags & 131 & 1697 & 2 & 0.01 & 0.03 & 52 \\
\hline (unsp.) & & Bags & 286 & 3994 & 14 & 0.03 & 0.06 & 365 \\
\hline U metal & Spain & Drums & 0.08 & 1.15 & 1 & $1.24 \mathrm{e}-6$ & $1.28 \mathrm{e}-8$ & 26 \\
\hline $\mathrm{UF}_{6}$ & EU & Cylinders & 26 & 153 & 5 & $2.80 \mathrm{e}-5$ & $2.45 e-5$ & 130 \\
\hline $\mathrm{U}$ & Russia & Packages & 5.58 & 52.48 & 1 & $6.02 \mathrm{e}-6$ & $8.37 \mathrm{e}-6$ & 26 \\
\hline Rad sources & EU & Pieces & 3.04 & 30 & 2 & $3.30 \mathrm{e}-6$ & $4.80 \mathrm{e}-6$ & 52 \\
\hline
\end{tabular}

\section{F. Other Cargos of Interest}

We have identified other cargos of interest and the corresponding data is summarized in table 7. High $\mathrm{Z}$ material such as lead and tungsten are known for their radiation shielding properties. They are part of the base metal category in the HS code. They represent a very small fraction of total imports. However, these results do not include lead or tungsten parts of manufactured goods, such as filaments, milling and drilling tools or collimators made of 
tungsten.

Some commodities are classified as "Miscellaneous Cargo" or "Household goods”, without giving any specifics regarding the content. However, miscellaneous cargo is not a negligible fraction of all imported TEU at $2.43 \%$. The TEU-weighted density distribution plotted in figure 9 indicates that more than half of household goods have density lower than $0.1 \mathrm{~g} / \mathrm{cm}^{3}, 95 \%$ of household goods and $64 \%$ of miscellaneous cargo have density below $0.2 \mathrm{~g} / \mathrm{cm}^{3}$, and 99.6\% of household goods and 94\% of miscellaneous cargo have density lower than $0.4 \mathrm{~g} / \mathrm{cm}^{3}$. Finally, a small fraction of containers are empty when shipped to the US, and some shipments consist of arms and ammunitions, and explosives with the latter being mostly fireworks.

TABLE 7: VARIOUS CARGO

\begin{tabular}{|l|r|r|r|r|c|c|}
\hline Product & TEU & $\begin{array}{r}\text { Weight } \\
\text { [ton] }\end{array}$ & $\begin{array}{r}\text { \#day } \\
\text { s }\end{array}$ & $\begin{array}{r}\text { TEU } \\
{[\% \text { total }]}\end{array}$ & $\begin{array}{r}\text { Weight } \\
{[\% \text { total }]}\end{array}$ & $\begin{array}{r}\text { \#days/yea } \\
\text { r }\end{array}$ \\
\hline Lead ores) & - & - & - & - & - & - \\
\hline Lead (articles) & 27.92 & 323 & 14 & $3.0 \mathrm{e}-3$ & $5.2 \mathrm{e}-3$ & 26 \\
\hline Tungsten (ores) & 21.83 & 280 & 12 & $2.4 \mathrm{e}-3$ & $4.5 \mathrm{e}-3$ & 312 \\
\hline Tungsten (articles) & 6.78 & 123.4 & 5 & $7.0 \mathrm{e}-4$ & $4.8 \mathrm{e}-6$ & 52 \\
\hline & & & & & & \\
\hline Household goods & 5969 & 20436 & 14 & 0.64 & 0.33 & 364 \\
\hline Misc. cargo & 22513 & 143582 & 14 & 2.43 & 2.29 & 364 \\
\hline Empty containers & 2104 & 8448 & 14 & 0.23 & 0.13 & 364 \\
\hline $\begin{array}{l}\text { Arms/ammunitions } \\
\text { (bomb, grenade, cartridges) }\end{array}$ & 315 & 1123 & 14 & 0.034 & 0.018 & 364 \\
\hline $\begin{array}{l}\text { Explosives (98\% } \\
\text { fireworks) }\end{array}$ & 1820 & 13420 & 14 & 0.2 & 0.21 & 364 \\
\hline
\end{tabular}

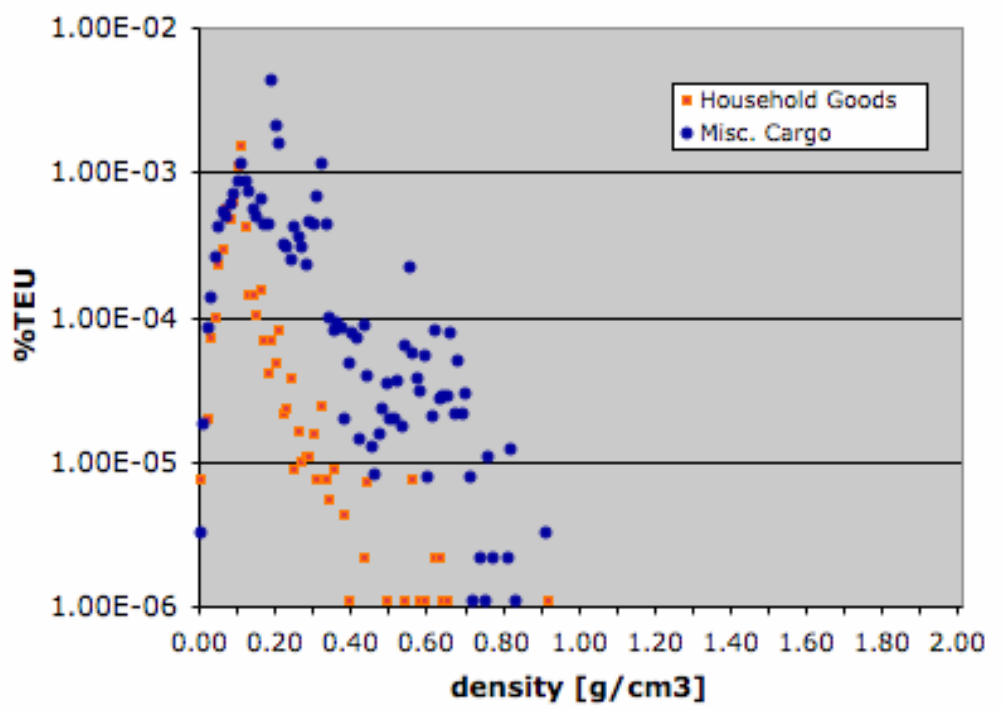

Figure 9. Density distribution for cargo categories: "Miscellaneous cargo” and "Household goods“

\section{G. Packaging}

A list of packaging categories is given in Appendix C. Figure 10 shows the number of records in the database associated with each category, while these results are weighted by the corresponding TEU in table 8. Although there are slight differences, close to $60 \%$ of commodities are packaged in cartons, and 90\% are packaged in cartons, pieces, packages cases, and boxes. Pallets represent only $0.51 \%$. Such a low frequency could be due to 1 ) access to low cost labor in Asia that favors hand loading of containers over palletization, 2) unlike pallets, cartons allow maximum container loading, i.e. the container is filled to the roof, and 3) it is also likely that some of these cartons 
or boxes are loaded on pallets.

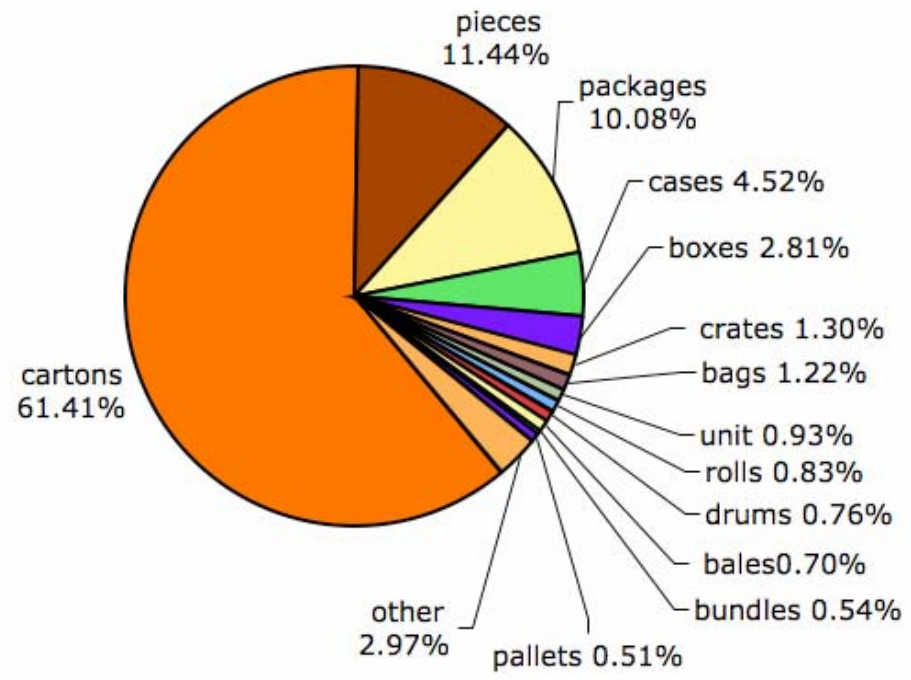

Figure 10. Distribution of cargo packaging (\% of records)

TABLE 8: CARGO PACKAGING

\begin{tabular}{|c|l|c|c|}
\hline Packaging code & Packaging & \% records & \% TEU \\
\hline CTN & Cartons & $61.41 \%$ & $58.29 \%$ \\
PCS & Pieces & $11.44 \%$ & $12.07 \%$ \\
PKG & Package & $10.08 \%$ & $12.06 \%$ \\
CS & Cases & $4.52 \%$ & $3.43 \%$ \\
BXS & Boxes & $2.81 \%$ & $2.85 \%$ \\
BGS & Bags & $1.22 \%$ & $1.49 \%$ \\
UNT & Units & $0.93 \%$ & $1.27 \%$ \\
CRT & Crates & $1.30 \%$ & $1.19 \%$ \\
BDL & Bundles & $0.54 \%$ & $0.84 \%$ \\
BLS & Bales & $0.70 \%$ & $0.82 \%$ \\
RLL & Rolls & $0.83 \%$ & $0.81 \%$ \\
BBG & Big bags & & $0.71 \%$ \\
DRS & Drums & $0.76 \%$ & $0.52 \%$ \\
SET & Sets & & $0.50 \%$ \\
PLT & Pallets & $0.51 \%$ & $0.50 \%$ \\
OTHER & & $2.97 \%$ & $2.68 \%$ \\
\hline
\end{tabular}




\section{FLUORINE: THE MAIN INTERFERENCE FOR 7 MEV NEUTRON ACTIVE INTERROGATION TECHNIQUE}

Active neutron interrogation is one of the cargo scanning techniques being investigated to detect SNM. The "nuclear carwash" project at LLNL, relies on the detection of delayed beta decay gammas emitted by fission product in the range 3 to $6 \mathrm{MeV}$. Cargo activation during scanning generate species emitting gammas in the energy range of interest, and could increase background and lower signal to noise ratio. This section describes our attempt at identifying and quantifying potential interferences. Possible reactions of 7 and $9 \mathrm{MeV}$ neutrons with most nuclei were considered. Since scanning time will be short, typically under a minute, we focus on activation products with half-life between $0.5 \mathrm{~s}$ and $10 \mathrm{mn}$ and emitting gammas above $3.0 \mathrm{MeV}$. Results are also presented for gamma threshold of 2.0 and 2.5 MeV. We used the specific activity in Bq/g defined in equation 2, as our metric to quantify the importance of various interferences:

$$
\operatorname{SpA}=Y_{\gamma} * \frac{N_{A} * \varepsilon^{*} \sigma}{A} * \frac{\ln 2}{T_{1 / 2}} \phi_{t}
$$

where $\mathrm{Y}_{\gamma}$ is the cumulative photon yield for gammas above threshold, $\mathrm{A}$ is the target mass, $\varepsilon$ the isotopic abundance, $\sigma$ the microscopic cross-section at 7 or $9 \mathrm{MeV}$, and $\phi_{\mathrm{t}}$ the neutron fluence set to unity.

Interferences with specific activities lower than 10e-8 Bq/g are not represented in figure 11 to 12 below. Figure 11 shows neutron reaction generating activation products in terms of specific activity (SpA) for 7 and $9 \mathrm{MeV}$ neutrons. Regardless of neutron energy the main interference is fluorine, ${ }^{19} \mathrm{~F}(\mathrm{n}, \mathrm{a}){ }^{16} \mathrm{~N}$, it is a least four orders of magnitude larger than other interferences. It was confirmed experimentally.[7] Lowering the gamma threshold to $2.5 \mathrm{MeV}$, adds one small interference, ${ }^{23} \mathrm{Na}(\mathrm{n}, \mathrm{p}){ }^{23} \mathrm{Ne}$. For a $2.0 \mathrm{MeV}$ gamma threshold, six more interferences are added, three of which have specific activities still three orders of magnitude lower than ${ }^{19} \mathrm{~F}$. The same trend is observed for $9 \mathrm{MeV}$ neutrons. The gamma detection threshold could be lowered from $3 \mathrm{MeV}$ to $2.5 \mathrm{MeV}$, to benefit from additional beta delayed gamma emission by fission products in that energy range.

In Figure 12, we compare 7 and $9 \mathrm{MeV}$ interferences for the three gamma thresholds. For a threshold of $3 \mathrm{MeV}$, increasing the neutron energy from 7 to $9 \mathrm{MeV}$ introduces one additional interference with a specific activity greater than 1.e-8 Bq/g, due to the reaction ${ }^{18} \mathrm{O}(\mathrm{n}, \mathrm{a}){ }^{15} \mathrm{C}$. This statement remains true when the gamma threshold is lowered to $2.5 \mathrm{MeV}$.
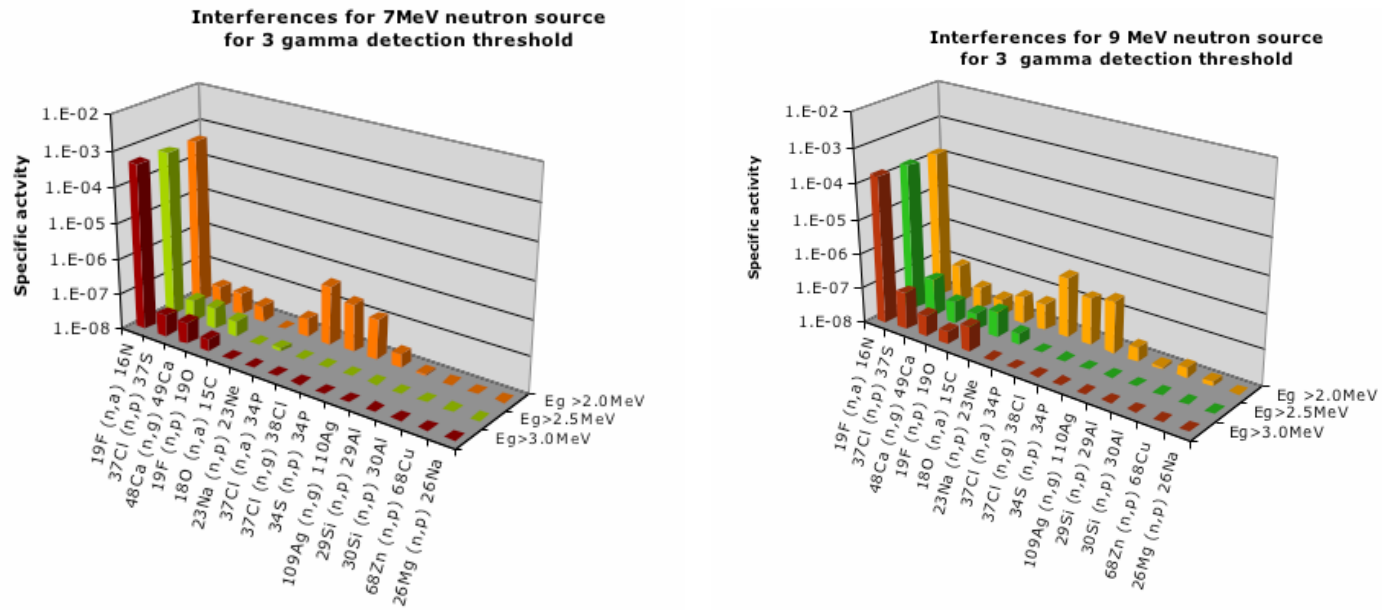

Figure 11. Main interferences for neutrons source of a) $7 \mathrm{MeV}$ and b) $9 \mathrm{MeV}$ 

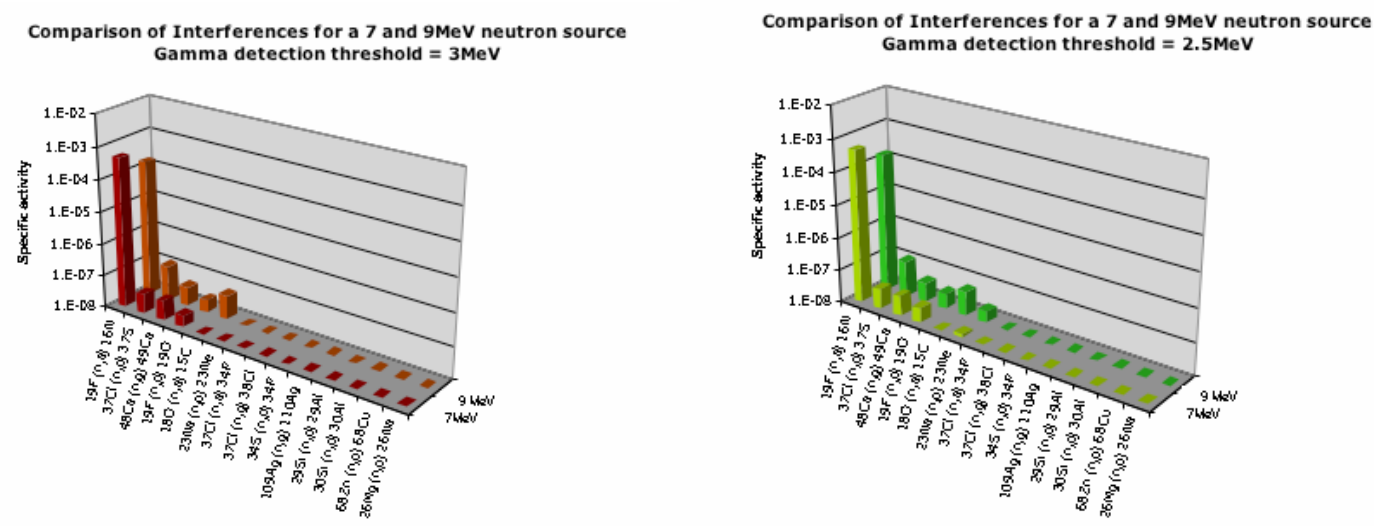

Comparison of Interferences for a 7 and $9 \mathrm{MeV}$ neutron source Gamma detection threshold $=2 \mathrm{MeV}$

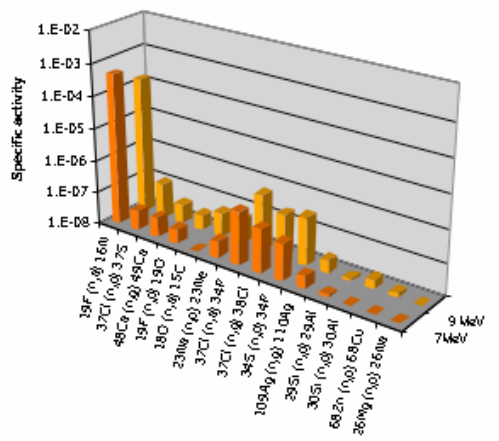

Figure 12. Comparison of interferences due to 7 and $9 \mathrm{MeV}$ neutrons for gamma detection threshold of a) $3.0 \mathrm{MeV}$, b) $2.5 \mathrm{MeV}$ and c) $2.0 \mathrm{MeV}$

Fluorine was identified as the dominant interference for neutron active interrogation of cargo. We analyzed the manifest data, focusing on fluorinated compounds and materials identified as such by shippers. We are aware that a non-negligible fraction of commodities probably contains fluorine, such as Teflon coating, or Teflon parts. However, these commodities should have lower concentration of ${ }^{19} \mathrm{~F}$ than fluorinated chemicals.

Declared fluorinated commodities represent a small fraction of the total traffic, $0.06 \%$ by TEU and $0,15 \%$ of the total cargo weight. These cargoes are imported through 18 ports, mainly New York (30\%), Charleston (19\%) and Los Angeles (15\%), Houston (7\%), Long Beach (6\%) and New Orleans (5\%) (see figure 13 and 14).

Fluorinated compounds and materials were organized in 36 categories based on the COM4 description defined by PIERS. Figure 15 shows that the large majority, close to $70 \%$, falls in the category of halogenated hydrocarbons, $\sim 5 \%$ are benzenoid chemicals, another $5 \%$ are synthetic resins and plastic once grouping various categories containing Teflon or PTFE, 2.7\% is Uranium fluoride, Potassium and ammonium compounds, hydrofluoric acid and toilet preparation, each just above $2 \%$. The five shipments of uranium fluoride came from Europe, and were unloaded in the ports of Baltimore and Norfolk. They represent $2.7 \%$ by TEU of the fluorinated compounds.

Table 9 contains chemical compounds belonging to the six main COM4 categories, as well as their atomic composition, molecular weight, and fluorine weight fraction, which varies from 16 to $86 \%$. For each record, the cargo weight is converted to a fluorine content per TEU using equation 2. Note that the packaging weight is neglected, therefore the fluorine amounts will be overestimated. But the fluorine content that cannot be identified on the basis of the manifest entries probably is much greater than this overestimate.

$$
\text { Weight }_{19}=\text { wp }_{1_{F}} * \text { Weight }_{\text {cargo }} / N
$$

where $\mathrm{wp}_{19 \mathrm{~F}}$ is the weight fraction of ${ }^{19} \mathrm{~F}$ in a compound, and $\mathrm{N}$ is the number of TEUs. In most cases, the fluorine content is greater than 1 metric ton per TEU, which means that in a scanning configuration, the $6.1 \mathrm{MeV}$ gamma line emitted by ${ }^{16} \mathrm{~N}$ should be prominent. 


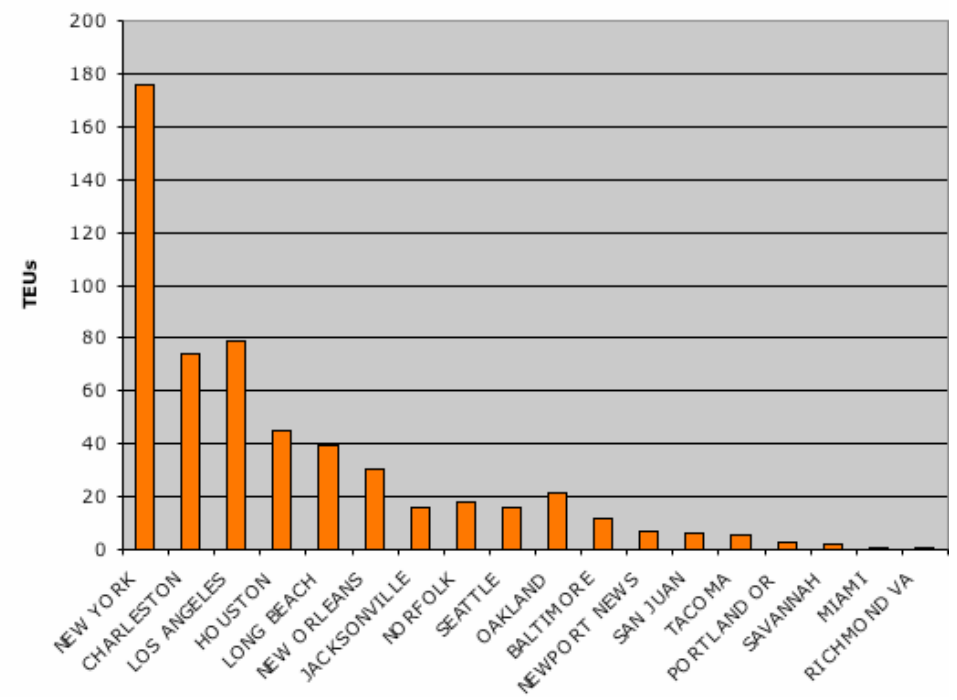

Figure 13. US imports of fluorinated compounds per port in TEU

Declared Fluor Compounds [\%TEU]

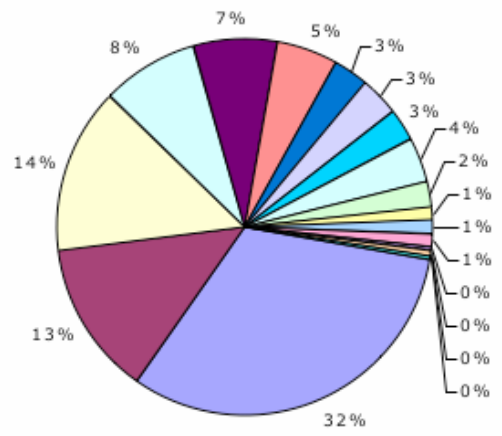

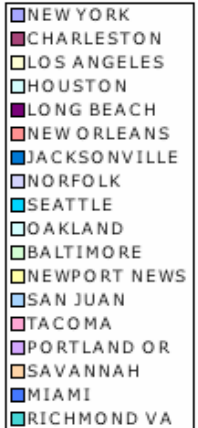

Figure 14. Ports receiving fluorinated compounds

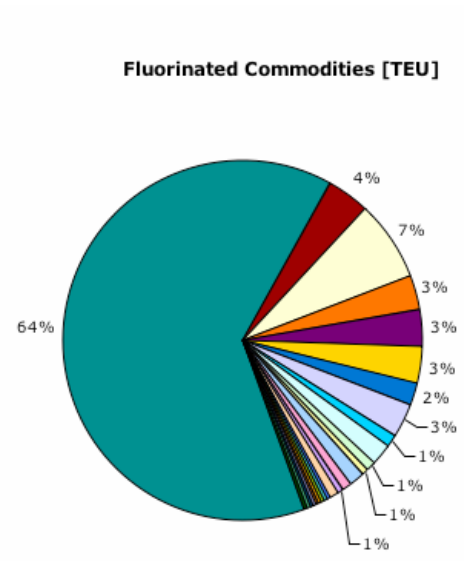

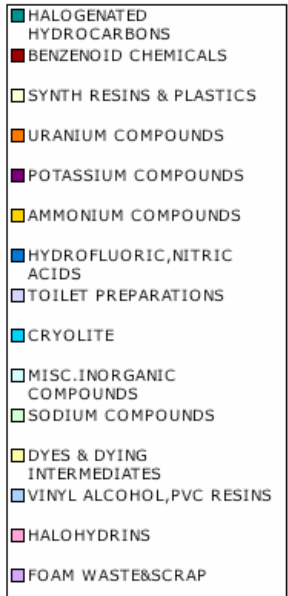

Figure 15. categories of fluorinated materials sorted by COM4 description in percent of total weight in TEU 
TABLE 9: ATOMIC COMPOSITION OF FLUORINATED COMPOUNDS

\begin{tabular}{|c|c|c|c|c|c|}
\hline COM4 description & Commodity & Formula & $\begin{array}{l}\text { Molecular } \\
\text { weight }\end{array}$ & \#atoms & Wgt \% \\
\hline Halogenated compounds & $\begin{array}{l}\text { Dichlorofluoroethane } \\
\text { chlorodifluoromethane } \\
\text { Difluoromethane } \\
\text { difluoroethane un1030 } \\
\text { Trifluoroethane } \\
\text { tetrafluoromethane un1982 } \\
\text { tetrafluoroethane un3159 } \\
\text { pentafluoroethane un3220 } \\
\text { Hexafluoropropane } \\
\text { hexafluoroethane un2193 } \\
\text { Heptafluoropropane } \\
\text { octafluorocyclobutane } \\
\text { bromotrifluoromethane }\end{array}$ & $\begin{array}{l}\mathrm{C} 2 \mathrm{H} 3 \mathrm{Cl} 2 \mathrm{~F} \\
\mathrm{CHClF} 2 \\
\mathrm{CH} 2 \mathrm{~F} 2 \\
\text { C2H4F2 } \\
\text { C2H3F3 } \\
\text { CF4 } \\
\text { C2H2F4 } \\
\text { C2HF5 } \\
\text { C3H2F6 } \\
\text { C2F6 } \\
\text { C3HF7 } \\
\text { C4F8 } \\
\text { CBrF3 }\end{array}$ & $\begin{array}{l}116.95 \\
86.47 \\
52.02 \\
66.06 \\
84.05 \\
88.00 \\
102.03 \\
120.03 \\
152.04 \\
138.02 \\
170.03 \\
200.03 \\
148.92\end{array}$ & $\begin{array}{l}1 \\
2 \\
2 \\
2 \\
3 \\
4 \\
4 \\
4 \\
5 \\
6 \\
6 \\
7 \\
8 \\
3\end{array}$ & $\begin{array}{l}16.24 \% \\
43.94 \% \\
73.04 \% \\
57.52 \% \\
67.81 \% \\
86.36 \% \\
74.48 \% \\
79.14 \% \\
74.97 \% \\
82.59 \% \\
78.21 \% \\
75.98 \% \\
38.27 \%\end{array}$ \\
\hline Benzenoid chemicals & $\begin{array}{l}\text { chlorobenzotrifluoride un2234 } \\
\text { dichlorobenzo trifluoride un3082 } \\
\text { fluorobenzene un2378 } \\
\text { metatrifluoromethylaniline un2948 }\end{array}$ & $\begin{array}{l}\text { C7H4ClF3 } \\
\text { C7H3Cl2F3 } \\
\text { C6H5F } \\
\text { C7H6F3N }\end{array}$ & $\begin{array}{l}180.56 \\
215.00 \\
96.11 \\
161.13\end{array}$ & $\begin{array}{l}3 \\
3 \\
1 \\
3\end{array}$ & $\begin{array}{l}31.57 \% \\
26.51 \% \\
19.77 \% \\
35.37 \%\end{array}$ \\
\hline Synthetic resins & polytetrafluoroethylene & $\mathrm{C} 2 \mathrm{~F} 4$ & 100.02 & 4 & $75.98 \%$ \\
\hline Uranium compounds & enriched uranium hexafluoride fissile & UF6 & 352.02 & 6 & $32.38 \%$ \\
\hline potassium compounds & $\begin{array}{l}\text { potassium fluorborate } \\
\text { potassium fluoride } \\
\text { Potassium hexafluorozirconate } \\
\text { potassium titanium fluoride }\end{array}$ & $\begin{array}{l}\text { KBF } 4 \\
\text { KF } \\
\text { K2ZrF } 6 \\
\text { F6K2Ti }\end{array}$ & $\begin{array}{l}125.90 \\
58.10 \\
283.40 \\
240.05\end{array}$ & $\begin{array}{l}4 \\
1 \\
6 \\
6\end{array}$ & $\begin{array}{l}60.36 \% \\
32.70 \% \\
40.22 \% \\
47.49 \%\end{array}$ \\
\hline Ammonium compounds & Ammonium bifluoride & NH4F.HF & 57.04 & 2 & $66.61 \%$ \\
\hline
\end{tabular}




\section{SUMMARY}

Several active interrogation techniques are being developed to detect special nuclear materials (SNM) hidden in cargo containers. To better understand the various aspects of containerized cargo, we analyzed shipping manifests for US imports shipped through North American ports collected on 14 days distributed over 12 months. The dataset was obtained from PIERS Global Intelligence Solutions. From these data, we determined various distribution functions of interest to the cargo scanning community, such as average densities, commodity categories, or packaging types. The main conclusion are:

- 12 US ports handle more than 94\% of traffic in TEU. The ports of Los Angeles and Long Beach alone handle almost half of the total US imports. As a first step, we can focus secondary screening on just a few US ports.

- The mean cargo density is just under $0.2 \mathrm{~g} / \mathrm{cm}^{3}$ and $98 \%$ of densities shown here are below the theoretical limit of $0.65 \mathrm{~g} / \mathrm{cm}^{3}$. If it is true that average densities are mainly below $0.4 \mathrm{~g} / \mathrm{cm}^{3}$, then most commodities should be cleared by primary screening techniques based on radiographic systems. Secondary screening techniques will focus on cargos with density greater than $0.4 \mathrm{~g} / \mathrm{cm}^{3}$.

- There are four categories of commodities accounting for nearly half of the total traffic by volume. They are furniture and toys, heavy machinery, textiles, and base metals. Organic products represent close to $60 \%$ of US imports while $28 \%$ of commodities are metal based. The remaining $12 \%$ consists of products made of stone, ceramics, mineral products, work of art and others.

- The majority of containers are 40 feet long, a fact consistent with the prevalence of imports with average density close to $0.1 \mathrm{~g} / \mathrm{cm}^{3}$ such as toys, furniture, and textiles, and with the prevalence of cartons over pallets as the preferred form of packaging.

- The neutron active interrogation currently developed at LLNL is based on neutron active interrogation and relies on the unique signature of beta-delayed gammas emitted by fission products in the 3 to $7 \mathrm{MeV}$ energy range. The reaction ${ }^{19} \mathrm{~F}(\mathrm{n}, \mathrm{a}){ }^{16} \mathrm{~N}$ has been identified as the main potential interference. Estimates of cargo compositions based on records identified as containing fluorine show that in most cases, the fluorine content is greater than 1 metric ton per TEU, which means that the $6.1 \mathrm{MeV}$ gamma line emitted by ${ }^{16} \mathrm{~N}$ will contribute significantly to the active background.

Finally, it would be of great interest to compare average densities obtained from the PIERS dataset to actual cargo density measurements.

\section{ACKNOWLEDGMENT}

The authors would like to thank Susan Tarver at PIERS Global Intelligence Solutions for helping us understand the data set, and Professor Prussin for the very productive discussions that we had during the analysis.

\section{REFERENCES}

[1] http://www.marisec.org/shippingfacts/ (Source: Lloyd's Register Fairplay January 2006)

[2] http://www.marad.dot.gov/MARAD statistics/index.html

[3] E. Norman, et al., NIMA 521/2, pp. 608, 2004. 
[4] D. Slaughter, et al., "Detection of special nuclear material in cargo containers using neutron interrogation," LLNL, Livermore, CA, UCRL-ID-155315, 2003.

[5] D. Slaughter, et al., NIMB 241, pp. 777-781, 2005

[6] J. M. Hall, et al., "The Nuclear Car Wash: Neutron interrogation of cargo containers to detect hidden SNM" submitted for publication in NIMA, 2006

[7] J. Church, et al, "Signals and interferences in the Nuclear Car wash," submitted for publication in NIMA 2006

[8] http://www.foreign-trade.com/reference/hscode.htm

[9] "PIERS: Global Intelligence Solutions" http://www.piers.com/

[10] http://www.dole5aday.com/ReferenceCenter/NutritionCenter 


\section{APPENDIX A -- HARMONIZED SYSTEM CODES FOR COMMODITY CLASSIFICATION}

\section{HS code Categories}

\section{0}

01 live animal

02 meat \& edible meat

03 fish \& crustacean

04 dairy, egg, honey \& edible pdcts

05 pdcts of animal origin

06 live trees \& other plants

07 edible vegetables

08 ed. fruits $\&$ nuts, peel of citrus/melons

09 coffee, tea, mate $\&$ spices

10 cereals

11 milling industry products

12 oil seeds/misc grains/med plants/straw

13 lac, gums, resins, etc

14 vegetable plaiting materials

15 animal or veg. fats, oil, waxes

16 ed. prep of meat, fish, crustacean, etc

17 sugar \& sugar confectionery

18 cocoa \& cocoa preparations

19 prep. of cereals, flour, starch or milk

20 prep. of veg, fruits, nuts, etc.

21 misc edible prep.

22 beverages, spirits $\&$ vinegar

23 residue from food industries, animal feed

24 tobacco \& manuf, tobacco substitutes

25 salt, sulfur, earth and stone, lime \& cement

26 ores, slag \& ash

27 mineral fuels, oils, waxes \& bituminous sub.

28 inorg. chem, org/inorg compounds of precious metal, isotopes

29 organic chemicals

30 pharmaceutical products

31 fertilizers

32 tanning or dyeing extracts, dyes, pigments, paints...

33 oils \& resinoids, perfurmery, cosmetics or toilet preps

34 soap, waxes, scouring products, candles, modeling pastes, dental waxes

35 albuminoidal sub, starches, glues, enzymes

36 explosives, matches, pyrotechnic products

37 photographic or cinematographic goods

38 miscellaneous chemical products

39 plastic \& articles thereof

40 rubbers $\&$ articles thereof

41 raw hides $\&$ skins \& leather

42 art. Of leather, saddlery * harness, travel goods, handbags articles of guts

43 furskin \& artif. fur, manufactures

44 wood \& art. Of wood, wood charcoal

45 cork \& articles of cork 
94 furniture, bedding, cushions, lamps \& lighting fitting nesoi, illuminated signs, nameplate $\&$ the like, $p$

manuf. of straw, esparto, basketware \& wickerwork

pulp of wood, waste $\&$ scrap of paper

paper \& paperboard, articles of paper pulp

printed books, newspapers, pictures, manuscripts, typescripts $\&$ plans

silk, inc. yarns \& woven fabrics

wool \& fine or coarse animal hair, inc yarns \& woven fabrics thereof

Cotton, inc yarns \& woven fabrics thereof

veg. textile fibers nesoi, yarns $\&$ woven etc

man-made filaments, inc. yarns $\&$ woven etc.

man-made staple fibers, inc, yarns, etc.

wadding, felt $\&$ non woven, special yarns, twine, corde, ropes $\&$ cables $\&$ art.

carpets $\&$ other textile floor coverings

special woven fabrics, tufted textile floor coverings

impregnated, coated, covered, or laminate textile prod, textile prod for indus. sse

knitted or crocheted fabrics

art. Of apparel \& clothing accessories-knitted or crocheted

art. Of apparel \& clothing accessories-not knitted or crocheted

made- up textile art. nesoi, needlecraft sets, worn clothing, rags

footwear, gaiters \& the like

headgear \& other parts

umbrellas, sun umbrellas, walking stick, whips, riding-crops 7 parts

prepared feathers, human hair \& articles thereof, artificial flowers

art. of stone, plaster, cement, asbestos, mica, or similar materials

ceramic products

glass \& glassware

pearl, stones, precious metals, imitation jewelry

iron \& steel

art. of iron \& steel

copper $\&$ art. Of copper

nickel $\&$ art. of Nickel

aluminium \& art. Thereof

lead $\&$ articles thereof

zinc $\&$ articles thereof

tin $\&$ articles thereof

base metal, NESOI, cermets, art. Etc..

tools, spoons \& fork of base metal

misc. art. Of base metal.

Nuclear reactors, boilers, machinery \& mechanical appliances, computers

electrical machinery $\&$ equipment $\&$ parts, telecommunications equip, sound recorders, TV recorders

railway or tramway locomotives, rolling stocks, track fixtures 7 fitting signals

vehicles other than railways or tramway rolling stock

aircraft, spacecraft \& part thereof

Ships, boats \& floating structures

optical, photographic, cinematographic, measuring, checking, precision, medical or surgical instrume clocks \& watches \& parts thereof

musical instruments, parts $\&$ accessories

Arms \& ammunition, parts \& accessories 
95 toys, games $\&$ sports equip., parts $\&$ access.

96 misc. manufactured articles

97 work of art, collectors' pieces, antiques 


\section{APPENDIX B -- PIERS 2000 FIELDS \& DESCRIPTIONS}

\section{Date \& Trade Direction}

DIR. A single character field representing cargo direction. There are two potential values: 'E' for exports (waterborne cargoes exiting the U.S.), "I" for imports (waterborne cargoes entering the U.S.).

VDATE. A six-character date field in the form year-month-day (YYMMDD). This is a mandatory field used for data collection. For US Exports, this would be the date the vessel left the US port. For US Imports, it is the date of arrival into a US port by that vessel. The VDATE is always associated with the US port. It displays in a report in 8 spaces: Jan 20, 1997 would be 97/01/20.

YRMTDY. An alpha version of VDATE most often used for downloading. It can be used in reports as well and displays in 6 characters without the slashes used in VDATE. The VDATE Jan 20, 1997 would display as 970120 .

MONTH. A four character date field in the form year-month (YYMM). Jan. 1997 would display in 5 spaces as $97 / 01$

YRMTH. The same as MONTH, it displays in four spaces without the separating slash mark. For Example 9701. This alpha version of month is also used for downloading.

QTR. This is a translated VDATE field. It displays in a report in 5 spaces. Jan/Mar 1997 would be 97 Q1. The first 2 characters are for the quarter (Q1, Q2, Q3, Q4).

QTRA. An alpha version of QTR used for downloading. It displays in four spaces without blanks. An example is $97 \mathrm{Q} 1$.

\section{OTHER VDATE FIELDS}

* YR The first two characters of Vdate representing the year.

* YRA The alpha version of YR.

* MT The middle two characters of VDATE and represents months.

* MTA The alpha version of MT.

* DY The day portion and last two characters of VDATE.

* DYA The alpha version of DY

* QT The last 2 characters from the QTR field (Q1)

* QTX 2 characters (1_) the quarter value followed by a blank.

\section{Production Description}

COMMODITY. A 35 character field that describes the product. It is copied exactly as written from the manifest or the bill of lading. This is not a standard description, it is the description of the cargo as manifested. This field contains the most varied descriptions of the product. It can be retrieved and used with any of the code fields that group commodities. Truncated versions of this field are COMMODITY30, COMMODITY25, COMMODITY20, and COMMODITY15, where the trailing number indicates the number of characters.

COMCODE. A seven-digit coding scheme that has been traditionally used by PIERS to classify the product or products being shipped. It is loosely based on the 1979 TSUSA commodity coding schedule. There are over 2,000 codes describing all products in the PIERS database. This comcode is separate from the Harmonized Tariff Schedule. (HSCODE). 
COM7_DESC. A 35 character field denoting a standard description based upon the seven digit COMCODE. It is used for summary reports when the actual manifest description is too detailed and aggregation is desired. Truncated versions are COM7_DESC30, COM7_DESC25, COM7_DESC20 and COM7_DESC15, where the trailing number indicates the number of characters.

COM4. A four-digit commodity code derived from the first four digits of the seven digit COMCODE. It groups the products into broader categories. There are under 1,000 COM4 codes. For example the COM4 code 1409 encompasses vegetables, where as COMCODE 140900T is tomatoes and COMCODE 140900A is onions.

COM4_DESC. A 30 character field denoting a standard description based upon the four digit COM4 code. Useful for summary reports when the actual manifest description is too detailed and aggregation is desired. Truncated versions are COM4_DESC25, COM4_DESC20, and COM4_DESC15, where the trailing number indicates the number of characters.

HSCODE. (6 digit level) A six-digit field denoting the Harmonized Tariff code for all products and commodities. This code is applied by PIERS based on the Harmonized Tariff Schedule. It is not copied from the document because it is not available on all documents. We track the HSCODE to the first six digits. There are over 4,000 codes. This coding scheme is more discreet than the traditional PIERS COMCODE. There is no correlation between the two coding schemes.

HARM_DESC. Formerly H6E_DESC and H6I_DESC. A 50 character field denoting a standard description based upon the six-digit HSCODE. All fieldnames yield the same standard description.

HARM4. A four-digit code derived from the first four digits of the six digit HSCODE. It groups the products into broader categories. There are slightly more than 2,000 HARM4 codes.

H4I_DESC/H4E_DESC. A 50 character field denoting a standard description based upon the four digit HARM4. H4I_DESC is used for import data and H4E_DESC is used for export data.

\section{Geographic Indicators}

CTRYCODE. A three-character field depicting the code used for each country. The fields CTRYCODE \& COUNTRY identify the origin of cargo for import data, destination for export data. It is based on the 1979 version of Schedule K, with modifications such as all the Russian Republic codes, the Middle East, etc.

\section{COUNTRY. A seven-character alphabetic description of CTRYCODE.}

COUNTRYL. A longer 25 character alphabetic description of CTRYCODE. The spelling for this field is more descriptive than can be achieved in the abbreviated 7-character COUNTRY field.

USCODE. A four-character port code field based upon the 1979 version of the US Customs' Schedule D. The USCODE represents the port in the U.S. that cargo crossed. For exports it is the load port, for imports it represents the arrival port. It does not have a one-to-one relationship with USPORT, more than one USPORT can share a USCODE.

USPORT. A 13 character alphabetic port name. This field is associated with USCODE. Truncated versions are USPORT11, USPORT09, USPORT07, \& USPORT05, where the trailing number indicates the number of characters.

FCODE. A five-character foreign port code based on the 1979 version of Schedule K. The first three characters identify the country location for this port. These codes are not unique since smaller ports within 
a country are grouped together into a single code. This port code represents the load port for import cargo and the discharge port for export cargo.

FPORT. A 13 character alphabetic description of the foreign port. Truncated versions are FPORT11, FPORT09, FPORT07, \& FPORT05, where the trailing number indicates the number of characters.

ULTCODE. Like the FCODE/FPORT relationship, this is a five-character code based on the 1979 version of Schedule K. When the ULTCODE/ULTPORT is a water port it will use Schedule K code.

For US Exports, the ULTCODE/ULTPORT represent the ultimate destination for the cargo as per the contract between the exporter and the ship line as reflected on the ship's manifest. The ultimate destination may be:

* an inland point

* a second deep water port (when transshipped)

* the same as the foreign port

For Imports, the port of origin would be the origin point. The original place where the steamship line accepts the cargo. This origin point / port may be:

* an inland port

* a deepwater port where the cargo is first located before being transshipped at the FPORT

* the same as the foreign port

When the ULTPORT is not a water port but an interior point, the code is based on a bucket category with the 1st three characters identifying the country. For example, Brussels would be 42300 since it pertains the 423 Belgium country code.

ULTPORT. A 13 character alphabetic description of the field ULTCODE. Truncated versions are ULTPORT11, ULTPORT09, ULTPORT07, \& ULTPORT05, where the trailing number indicates the number of characters.

USIB_CODE. A four-digit code (formerly USFINAL), contains the U.S. Customs clearing point other than the discharge port. This information is supplied on the AMS tape for Imports only.

USIB_CITY. A 13 character alphanumeric field containing the city name corresponding to the USIB_CODE.

USIB_ST. A seven-character alphanumeric field containing the 2 character state code corresponding to USIB_CODE.

ORG_DES_CITY. This 13 character alphanumeric field contains the origin city for export cargo, destination city for import cargo. This field is blank when no origin/destination city is indicated on the shipping documents.

ORG_DES_ST. This seven-character alphanumeric field contains the origin state or country for export cargo, destination state or country for import cargo. This field is blank when no origin / destination state or country is indicated on the shipping documents.

FGNIB_CODE. A five-digit code, same as the foreign port code, indicating the foreign customs clearing district. This information is supplied on the AMS tape for Imports only.

FGNIB_CITY. A 13 character alphanumeric field containing the city name corresponding to the FGNIB_CODE. 
FGNIB_CTRY. A seven-character alphanumeric field containing country name corresponding to FGNIB_CODE.

\section{Shippers, Consignees \& Notify Parties}

NAME. A 35 character field consisting of the company name on the U.S. side of the transaction. For imports, this would be the consignee/importer of the goods as reported on the manifest. For exports, this would be the shipper/exporter of the goods as described on the bill of lading. All punctuation such as commas and periods are excluded from this field. Inc., Corp., Co., and other abbreviations at the end of a company name are not included, but others such as Intl for International are the exception.

When the name "ORDER" appears in this field, the name has been restricted. These companies can mask their name but cannot mask the details of their shipments. Companies must be approved for restriction by U.S. Treasury Dept. and are in effect for two years. Truncated versions are NAME30, NAME25, NAME20 and NAME15, where the trailing number indicates the number of characters.

CITY. A 13 character field depicting the city location of the company indicated by NAME as shown on the documents. This field may represent a headquarters location or a warehouse destination point. This field is blank when the ST field is ' $\mathrm{XX}$ '.

ST. A two-character code for the state. There are approximately 70 state codes, including U.S. postal abbreviations for states and territories, 10 Canadian provinces and the rest pertaining to select foreign entities.

The state code "XX" indicates an unknown location. The CITY for this transaction would be blank. The state code is "ZZ" when a foreign city appears in the CITY field and the country is not one of the selected few with a 2 character ST abbreviation.

STREET. A 35 character field containing an address for the company shown in the NAME field. Truncated versions are STREET30, STREET25, STREET20, and STREET15, where the trailing number indicates the number of characters.

STREET2. A 25 character field containing a second line of address for the company shown in the NAME field.

\section{ZIPCODE. A nine-character field depicting the zipcode / postal code of the company.}

COMP_NBR. The 14 character company number is created and assigned by PIERS. The first eight characters are the company number (unique to the company name regardless of the location); the next three characters are the city / st location within the company name; the last three characters are the locations within the city/state based on addresses.

MAIN_CMP_NBR. This eight-character company number contains the first 8 characters of COMP_NBR. The first eight characters are unique to the company name regardless of the location.

FNAME. A 35 character company name. It is exporter / shipper name for import cargo only. This field is blank for all export data. Like NAME, FNAME can be shown as "ORDER", but only when the company in the NAME field requests anonymity for itself and its suppliers. Truncate versions are FNAME30, FNAME25, FNAME20, and FNAME15, when the trailing number indicates the number of characters.

FCITY. A 13 character field depicting the city location of the foreign shipper company indicated by FNAME. This field can be blank. 
FCTRYCODE. A three-character US Customs Schedule K country code for the country location of the foreign shipper. This country code can differ from the country code of the origin of the goods or the loading port.

FCOUNTRY. A seven-character alpha description of the FCTRYCODE. It is listed as "ZZ" if the FCTRYCODE is unknown.

FCOUNTRYL. A 25-character alpha description for FCTRYCODE. The long version of FCOUNTRY.

FSTREET. A 35-character field of the street address of the company listed in FNAME. Truncated versions are FSTREET30, FSTREET25, FSTREET20, and FSTREET15, where the trailing number indicates the number of characters.

FSTREET2. A second line of street address 25 characters in length.

FZIPCODE. A nine-character field depicting the postal code of the FNAME.

FCOMP_NBR. The 14 character company number for the field FNAME. The code is created and assigned by PIERS. The first eight characters are the company number (unique to the company name regardless of the location). The next three characters are the FCITY / FCOUNTRY location within the company name. The last three characters are the location within the FCITY/FCOUNTRY based on the address given.

FMAIN_CMP_NBR. This eight-character company number for the exporter contains the leading characters contained in FCOMP_NBR. The first eight characters are unique to the FNAME regardless of location.

NFT_NAME. A 35 character company name indicating the notify party for goods imported to the U.S. Truncated versions are NTF_NAME30, NTF_NAME25, NTF_NAME20, and NTF_NAME15, where the trailing number indicates the number of characters.

NTF_CITY. A 13 character field depicting the city location of the notify party company indicated by NTF_NAME.

NTF_ST. A two-character code for the state of the notify party company indicated by NTF_NAME.

NTF_STREET. A 35 character field of the street address of the company listed in NTF_NAME. Truncated versions are NTF_STREET30, NTF_STREET25, NTF_STREET20, and NTF_STREET15, where the trailing number indicates the number of characters.

NTF_STREET2. A second line of street address 25 characters in length.

NTF_ZIPCODE. A nine-character field depicting the postal code of the NTF_NAME.

NTF_COMP_NBR. The 14 character company number for the field NTF_NAME. The first eight characters are the company number (unique to the company name regardless of the location). The next three characters are the city/state location within the company name. The last three characters are the location within the city/state based on the address given.

\section{Carrier \& Shipment Details}

SLINE. A four character alphabetic steamship line carrier code. It is created by PIERS. This code identifies the ship line that transported the cargo. 
VESSEL. A 17 character alphabetic vessel name. This is the name of the waterborne vessel calling at the U.S. port.

VESSEL_CODE. A seven-character code uniquely identifying a vessel. This is the Lloyd's vessel code. This appears only on import transactions.

REGISTRY. A seven character alphanumeric field containing the country name where the vessel is registered, commonly known as the vessels flag or nationality.

VOYAGE. An eight-character voyage number unique within the steamship line.

MANIFEST_NBR. A six-character code that U.S. Customs assigns to the vessel call. This number is uniquely based on USPORT, VESSEL, VDATE and DIR. On vessels that are shared, the Manifest Number would pertain to all things.

BOL_NBR. A 12 character code identifying the bill of lading number. It is assigned by the ship line.

QTY. A 9 digit numeric field denoting the quantity of the unit of measure.

U_M. A three-character unit of measure field. The unit of measure identifies the type of packaging. The number of packages value in the QTY field.

REEFER. A single character field. Cargoes that are refrigerated will have a ' $Y$ '. This field will be blank for all other shipments.

RORO. A single character field. Cargoes that considered roll on / roll off in nature are assigned the code ' $Y$ '. This field will be blank for all other shipments.

HAZMAT. A single character field. Cargoes that are hazardous material will be assigned the code ' $\mathrm{Y}$ ' in this field. This field will be blank for all other shipments.

NVOCC. A single-character field. Transactions are tested against an NVOCC table. When an export shipper is matched against this table the code ' $\mathrm{C}$ ' is assigned. For imports, when a consignee is matched against this table the code ' $\mathrm{C}$ ' is assigned. If the consignee does not match but the notify party name matches, the code ' $\mathrm{N}$ ' is entered. For all companies that do not match a listing in the Non Vessel Operating Common Carrier table, this field is left blank.

\section{Cargo, Weight \& Container Details}

CONFLAG. A single-character field. Cargoes that are moved in containers will have a 'C' in this field. This field will be blank for all other shipments.

CONSIZE. A two-character field denoting container size. If this field contains 'LC' (less than a container), the cargo would be a part of a full container move. The code ' $\mathrm{ZZ}$ ' would be for a full box when the size is unknown. All numerical values would be for the length of the container. For example: '20' Twenty-foot Containers; ‘40’ Fort-foot Containers. This field is blank for non-containerized records.

CONQTY. A five-digit integer field which is the count of the number of containers. Less than a container load (LC) will have a ' 0 ' in this field. All full box containers (20, 40, ZZ) will have a value assigned to this field. This field is ' 0 ' for all non containerized records.

CONVOL. A 15 digit numeric field that is the measurement of the cargo in cubic feet. (LxWxH). The data for this field is not always available on the source documents and is then displayed as ' 0 '. Unlike 
CONQTY and CONSIZE, which are only filled in when CONFLAG is equal to 'C', CONVOL is the cubic measure for containerized or non-containerized data.

TEUS. TEU means Twenty foot Equivalent Units. It is a calculated field that is 15 digits in length including two decimal places. When the records are describing full container loads, TEUS are calculated using CONSIZE and CONQTY. Partial container loads (LC) or unknown box sizes (ZZ), are calculated using a PIERS TEU reference table.

FEUS. FEU means Forty foot Equivalent Units. It is a calculated field that is 15 digits in length including two decimal places. FEUS equal CONSIZE times CONQTY divided by 40 when they are full container loads. Partial loads and unknown box sizes equal the TEUS value divided by two. For example: 6 TEUS equal 3 FEUS.

POUNDS. A 15 digit numeric field denoting the weight of the cargo. All weight is collected by PIERS in pounds. It is the basis for the calculated weight fields that follow.

MTONS. This Metric Tons field is calculated by dividing POUNDS by 2240.6. It is 12 digits including two decimal places.

LTONS. This Long Tons field is calculated by dividing POUNDS by 2240. It is 12 digits including two decimal places.

STONS. This Short Tons field is calculated by dividing POUNDS by 2000. It is 12 digits including two decimal places.

KILOS. This Kilos field is calculated by dividing POUNDS by 2.2046. It is 12 digits including two decimal places.

SHPMNTS. A seven-digit numeric field. The value is ' 1 ' for each record. A sum of the values in this field will give you the total shipments or transactions in a report.

\section{Financial \& Miscellaneous}

FINANCIAL. A single alphanumeric character. This flag field contains the value ' $\mathrm{Y}$ ' when the reporters keying in the PIERS record find a bank, financial institution, or letter of credit number on the source document. It is left blank for all other transactions.

BANK. A 35 character field containing the bank name. It is collected on import transactions that are sourced from the AMS tape.

PAYABLE. A single alphanumeric character. Cargoes moving on a freight collect basis are tagged ' $\mathrm{C}$ ', prepaid transactions are assigned ' $\mathrm{P}$ '. If the prepaid or collect field cannot be determined, this field will be left blank.

VALUE. This 15 digit numeric field contains the estimated value for the transaction. PIERS has built a reference table that incorporates the Department of Commerce waterborne values. The reference table is summarized by U.S. coast, Country and Hscode. There are separate tables for export and import transactions. The value is generated by multiplying the average value from the reference table by the metric tons (MTONS) field in the shipment.

PDATE. The PIERS' Process Date. Like VDATE, this is a six-character date field in the form of yearmonth-day (YYMMDD). This is the date the record enters the PIERS database. There is one Pdate per week that corresponds to the weekly database load. 
UDATE. The Update Date. Like VDATE, this is a six-character date field in the form of year-month-day (YYMMDD). When a record has been updated after it is loaded into the database, this UDATE is the date the change occurred.

RECNUM. The PIERS Record Number. A nine-character alphanumeric field assigned by PIERS to uniquely identify each individual record. No two records in the database will share the same record number. 


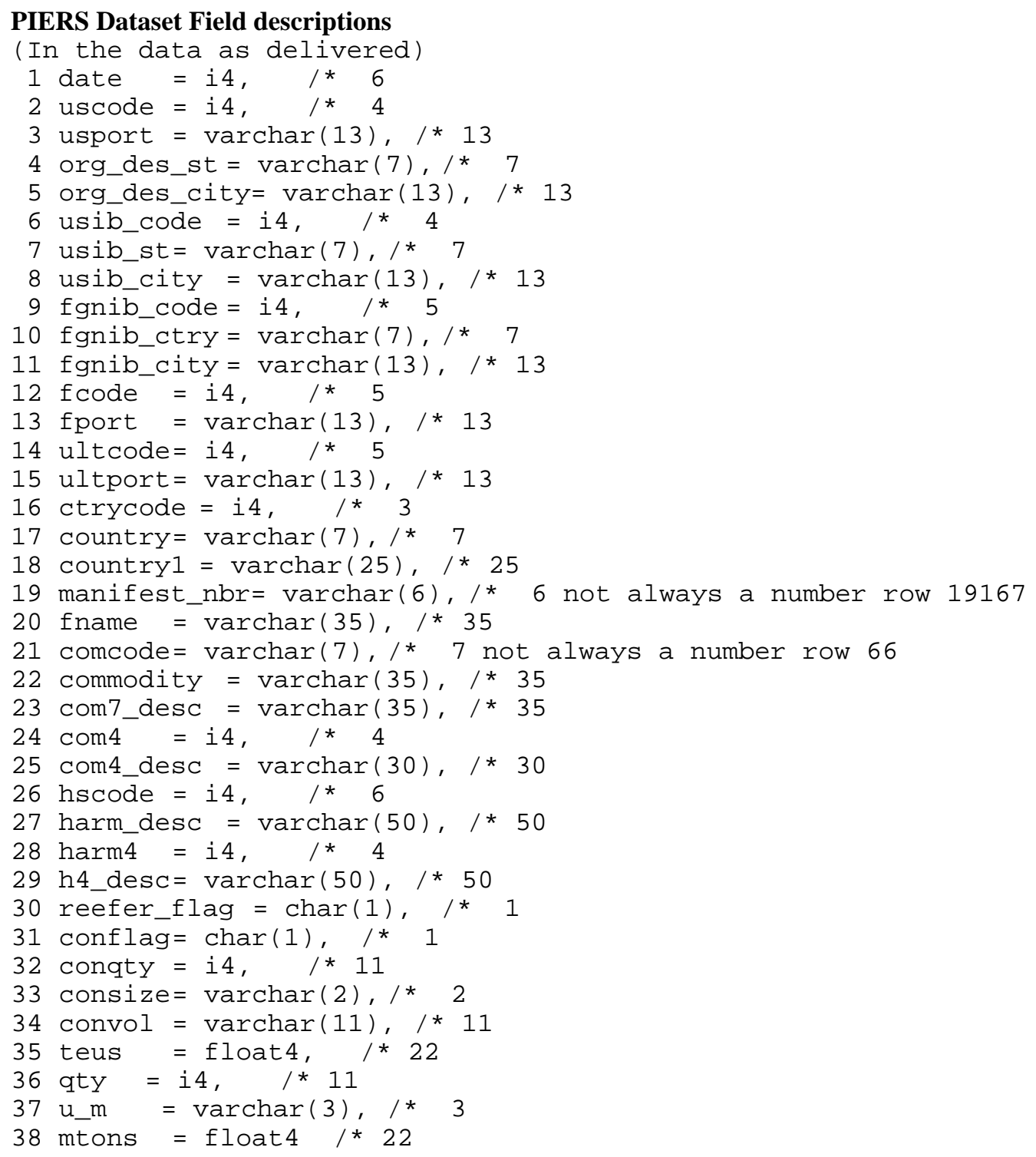




\section{APPENDIX C -- PIERS CARGO PACKAGING DESCRIPTION}

\begin{tabular}{|c|c|c|c|}
\hline$\underline{\mathrm{U} M}$ & Unit of Measure Description & $\underline{U M}$ & Unit of Measure Description \\
\hline BAL & BALLOTS & FBM & FOOT BOARD MEASURE \\
\hline BAR & BARS & FLK & FLASKS \\
\hline BBG & BIG BAGS & FLO & FLOAT CONTAINER \\
\hline BDL & BUNDLES & FLT & FLATS \\
\hline BGS & BAGS & FT & FEET \\
\hline BIN & BINS & GAL & GALLONS \\
\hline BKC & BULK CONTAINER & GRS & GROSS \\
\hline BKS & BULKS & $\mathrm{HBL}$ & H BARRELS \\
\hline BKT & BUCKETS & $\mathrm{HCH}$ & H CHEST \\
\hline BLK & BLOCKS & HCK & HALF CASK \\
\hline BLS & BALES & HCR & HOPPER CAR \\
\hline BMS & BEAMS & HCT & H CRATE \\
\hline $\mathrm{BOB}$ & BOBBINS & HDR & HALF DRUM \\
\hline BRG & BARGES & HDS & HANDS \\
\hline BRL & BARRELS & $\mathrm{HGH}$ & HOGHEADS \\
\hline BSH & BUSHELS & $\mathrm{HOB}$ & HOBBOCKS \\
\hline BSK & BASKETS & HPU & H PUNCHEON \\
\hline BTL & BOTTLE & ITM & ITEM \\
\hline BUN & BUNCHES & JAR & JARS \\
\hline $\mathrm{BXC}$ & BOX CAR & JUG & JUG \\
\hline BXS & BOXES & KGS & KEGS \\
\hline CAG & CAGES & LDS & LOADS \\
\hline CAN & CANS & LEG & LEGS \\
\hline CAR & CARRIER & LFT & LIFTS \\
\hline CAT & CATTIES & LIN & LINATINES \\
\hline CBM & CUBIC METERS & LNG & LENGTHS \\
\hline CBS & CAR BOYS & LOT & LOTS \\
\hline $\mathrm{CDL}$ & CRADLE & LOV & LOAVES \\
\hline CFT & CUBIC FEET & LTR & LITERS \\
\hline $\mathrm{CHR}$ & CHURNS & LUG & LUGS \\
\hline $\mathrm{CHT}$ & CHESTS & LVN & LIFT VAN \\
\hline CKS & CAKES & MIX & MIX \\
\hline $\mathrm{CL}$ & CAR LOAD & MST & MASTERS \\
\hline CLS & COILS & MTR & METERS \\
\hline $\mathrm{COL}$ & COLLI & OUT & OUT, OUTERS \\
\hline CON & CONTAINER & PBX & PALLET BOX \\
\hline CRD & CORDS & PCL & PARCELS \\
\hline CRT & CRATE & PCS & PIECES(LOGS,EMPTY BEAMS) \\
\hline CS & CASES & PKG & PACKS \& PACKAGE \\
\hline CSK & CASKS & PLS & PAILS \& PILES \\
\hline CTN & CARTONS, FIBERBOARD CONTAIN & PLT & PALLET \\
\hline CUB & CUBES & PNL & PANELS \\
\hline CYL & CYLINDERS & PRS & PAIRS \\
\hline DJS & DEMI JOHNS & PTS & PLATTER, PLATES \\
\hline $\mathrm{DOZ}$ & DOZEN & PUN & PUNCHEON \\
\hline DRS & DRUMS, FIBER DRUMS, POLY DR & QBL & QUARTER BARREL \\
\hline DSK & DISKS & $\mathrm{QCH}$ & QUARTER CHEST \\
\hline ENV & ENVELOPES & QDR & QUARTER DRUM \\
\hline$\underline{U} \mathbf{M}$ & Unit of Measure Description & & \\
\hline QTS & $\overline{\text { QUARTS }}$ & & \\
\hline
\end{tabular}




\begin{tabular}{ll} 
RCK & RACK \\
RLL & ROLLS \\
RLS & REELS \\
RMS & REMES \\
RNG & RINGS \\
SET & SETS \\
SFT & SQUARE FEET \\
SHT & SHEET \\
SKD & SKIDS \\
SKS & SACKS \\
SLG & SLING \\
SPL & SPOOL \\
SSK & SUPER SACK \\
STM & STEMS \\
SYD & SQUARE YARDS \\
TBS & TUBES \\
TIB & TIBS \\
TIE & TIES \\
TIN & TINS \\
TLB & TALLBOY \\
TLS & TAILS \\
TNK & TANK \\
TOT & TOTIS \\
TR & TRUCKLOAD \\
TRA & TRAYS \\
TRC & TIERCES \\
TRL & TRAILER \\
TRS & TRUSSES \\
TR & \\
W & TRIWALLS \\
TUB & TUBS \\
UNT & UNIT \\
VAN & VAN \\
YDS & YARDS \\
& NO UOM \\
& \\
\hline
\end{tabular}

